\title{
Observations of Saharan dust microphysical and optical properties from the Eastern Atlantic during NAMMA airborne field campaign
}

\author{
G. Chen ${ }^{1}$, L. D. Ziemba ${ }^{1,2}$, D. A. Chu ${ }^{3}$, K. L. Thornhill ${ }^{1,4}$, G. L. Schuster ${ }^{1}$, E. L. Winstead ${ }^{1,4}$, G. S. Diskin ${ }^{1}$, \\ R. A. Ferrare ${ }^{1}$, S. P. Burton ${ }^{1,4}$, S. Ismail ${ }^{1}$, S. A. Kooi ${ }^{1,4}$, A. H. Omar ${ }^{1}$, D. L. Slusher ${ }^{5}$, M. M. Kleb ${ }^{1}$, J. S. Reid ${ }^{6}$, \\ C. H. Twohy ${ }^{7}$, H. Zhang ${ }^{8}$, and B. E. Anderson ${ }^{1}$ \\ ${ }^{1}$ NASA Langley Research Center, Hampton, VA 23681, USA \\ ${ }^{2}$ Oak Ridge Associated Universities, Oak Ridge, TN 37831, USA \\ ${ }^{3}$ University of Maryland Baltimore County/NASA Goddard Space Flight Center, Greenbelt, MD 20771, USA \\ ${ }^{4}$ Science Systems and Applications, Inc Hampton, VA 23666, USA \\ ${ }^{5}$ Coastal Carolina University, Conway, SC 29528, USA \\ ${ }^{6} \mathrm{Naval}$ Research Laboratory, Monterey, CA 93943, USA \\ ${ }^{7}$ Oregon State University, Corvallis, OR 97331, USA \\ ${ }^{8}$ Georgia Institute of Technology, Atlanta, GA 30332, USA
}

Received: 30 March 2010 - Published in Atmos. Chem. Phys. Discuss.: 26 May 2010

Revised: 16 November 2010 - Accepted: 22 December 2010 - Published: 26 January 2011

\begin{abstract}
As part of the international project entitled "African Monsoon Multidisciplinary Analysis (AMMA)", NAMMA (NASA AMMA) aimed to gain a better understanding of the relationship between the African Easterly Waves (AEWs), the Sahara Air Layer (SAL), and tropical cyclogenesis. The NAMMA airborne field campaign was based out of the Cape Verde Islands during the peak of the hurricane season, i.e., August and September 2006. Multiple Sahara dust layers were sampled during 62 encounters in the eastern portion of the hurricane main development region, covering both the eastern North Atlantic Ocean and the western Saharan desert (i.e., $5-22^{\circ} \mathrm{N}$ and $10-35^{\circ} \mathrm{W}$ ). The centers of these layers were located at altitudes between 1.5 and $3.3 \mathrm{~km}$ and the layer thickness ranged from 0.5 to $3 \mathrm{~km}$. Detailed dust microphysical and optical properties were characterized using a suite of in-situ instruments aboard the NASA DC-8 that included a particle counter, an Ultra-High Sensitivity Aerosol Spectrometer, an Aerodynamic Particle Sizer, a nephelometer, and a Particle Soot Absorption Photometer. The NAAMA sampling inlet has a size cut (i.e., $50 \%$ transmission efficiency size) of approximately $4 \mu \mathrm{m}$ in diameter for dust particles, which limits the representativeness of the NAMMA observational findings. The NAMMA dust observations showed relatively low particle number densities,
\end{abstract}

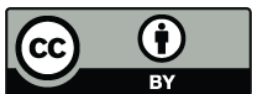

Correspondence to: G. Chen (gao.chen@nasa.gov) ranging from 268 to $461 \mathrm{~cm}^{-3}$, but highly elevated volume density with an average at $45 \mu \mathrm{m}^{3} \mathrm{~cm}^{-3}$. NAMMA dust particle size distributions can be well represented by tri-modal lognormal regressions. The estimated volume median diameter (VMD) is averaged at $2.1 \mu \mathrm{m}$ with a small range of variation regardless of the vertical and geographical sampling locations. The Ångström Exponent assessments exhibited strong wavelength dependence for absorption but a weak one for scattering. The single scattering albedo was estimated at $0.97 \pm 0.02$. The imaginary part of the refractive index for Sahara dust was estimated at 0.0022 , with a range from 0.0015 to 0.0044 . Closure analysis showed that observed scattering coefficients are highly correlated with those calculated from spherical Mie-Theory and observed dust particle size distributions. These values are generally consistent with literature values reported from studies with similar particle sampling size range.

\section{Introduction}

A recent analysis of MODIS (Moderate-Resolution Imaging Spectroradiometer) satellite observations indicates that an average of $240 \pm 80 \mathrm{Tg}$ of mineral dust is transported from the Saharan Desert each year downwind over the North Atlantic by the prevailing trade winds (Kaufman et al., 2005). These dust outbreaks occur frequently from spring to summer and are visually prominent in satellite imagery as

Published by Copernicus Publications on behalf of the European Geosciences Union. 


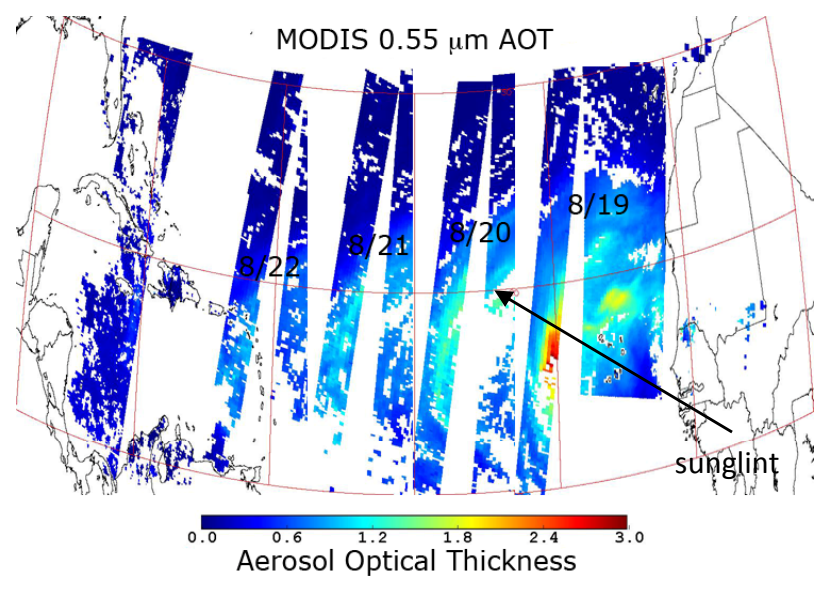

Fig. 1. Composite images of Terra MODIS AOT of a dust outbreak across the Atlantic Ocean from 19-22 August 2006. Sunglint is shown in white in the middle of the image.

illustrated by the August 2006 MODIS observations shown in Fig. 1. The dust is generally thought to be confined to a warm, dry "Saharan Air Layer" or SAL, which rides westward with the strong and steady North Atlantic trade winds up to approximately $6000 \mathrm{~km}$ from the North African coast in the summer. The SAL tends to be stable, possibly because of heating related to enhanced solar extinction by dust, and can maintain its integrity over extremely long distances reaching the western Caribbean Sea (Dunion and Velden, 2004). Using successive CALIPSO observations, Liu et al. (2008) tracked a clearly defined Saharan dust layer from its origin to the western Gulf of Mexico.

Ground-based and satellite measurements of aerosol optical thickness (AOT) indicate that Saharan dust layers often cover vast regions of the North Atlantic, which has led many to speculate that the SAL might have significant direct and indirect impacts on regional radiation budgets and hydrological cycles, including tropical storm development and intensification. Lau and Kim (2007) noted a strong negative correlation between dust loading and sea surface temperature (SST) in the hurricane development region of the eastern North Atlantic. By contrasting 2006 and 2005 satellite observations, these investigators further conjectured that lower SST and enhanced Saharan dust in 2006 may have been an important factor for the decreased hurricane activity in that year (Lau and Kim, 2007) as compared to 2005, which had one of the most active hurricane seasons in recent history. In a later study, Sun et al. (2008) pointed out the potential linkage between the activeness of hurricane seasons and dust loading in both the main development region (MDR, 10-20 ${ }^{\circ} \mathrm{N}$ and 15$65^{\circ} \mathrm{W}$ ) and the western North Atlantic (WNA). Using particle properties inferred from remote sensor measurements, Lau and Kim (2007) were able to crudely confirm the dust impact on SST, but they noted that accurate measurements of dust size distributions, optical properties and spatial distribu- tions within the MDR are needed to facilitate more accurate assessments of dust influence on the atmospheric radiation budget and implications to the development of the Atlantic hurricanes.

In addition to direct radiative cooling effects, Saharan dust can affect cloud formation and microphysical properties. Saharan dust is known to act both as efficient ice forming nuclei (IFN) at relatively warm temperatures in the upper troposphere (Demott et al., 2003; Sassen et al., 2003; Van den Heever et al., 2006) and as efficient cloud condensation nuclei $(\mathrm{CCN})$. Studies have indicated that dust particles act as $\mathrm{CCN}$ at relatively modest water vapor supersaturation (Rosenfeld et al., 2001; Twohy et al., 2009), which can affect precipitation rates, cloud microphysical and optical properties and, potentially, tropical storm development and intensification. Zhang et al. (2007) found that dust could act as CCN and induce changes in the hydrometeor properties, modifying the latent heat distribution and ultimately influencing the storm intensity through complex dynamical processes. In a more recent work, Zhang et al. (2009) showed that dust could indirectly affect the eyewall development by modifying the latent heat release in rainbands. Both studies note that more detailed observational information on Saharan dust microphysical properties and vertical distributions is needed to further develop a mechanistic understanding of the potential effects of dust on hurricane genesis and intensity.

A number of recent airborne and ground based field campaigns were conducted under the framework of African Monsoon Multidisciplinary Analysis (AMMA) international project (http://amma.mediasfrance.org/) to investigate, among other things, Saharan dust generation, transport and regional impacts. These studies were focused over the eastern Tropical Atlantic and North Africa and carried out various measurements of Saharan dust spatial distributions and characteristics, including optical, chemical, and microphysical properties. The Dust Outflow and Deposition to Ocean (DODO) campaign was conducted in Dakar, Senegal during February and August 2006 (McConnell et al., 2008); the Dust and Biomass-burning Experiment (DABEX) was conducted in January and February 2006, with an airborne component based in Niamey, Niger (Osborne et al., 2008); and the Saharan Mineral Dust Experiment (SAMUM), was also carried out in Southern Morocco during May and June in 2006 (Heintzenberg, 2009). To specifically improve understanding of the relationship between the African Easterly Waves (AEWs), the SAL, and tropical cyclogenesis, the NAMMA (NASA AMMA) field campaign was based on the Cape Verde Islands during August and September 2006 (Zipser et al., 2009). The airborne component of NAMMA consisted of 13 science flights operated from Sal Island and was primarily focused on the eastern portion of the MDR, covering both eastern North Atlantic and western Saharan desert (i.e., $5-22^{\circ} \mathrm{N}$ and $10-35^{\circ} \mathrm{W}$ ) during the peak of the hurricane season. In addition to AMMA associated studies, there were other Saharan dust studies, including the Saharan Dust 
Experiment (SHADE) operated from the Sal island of Cape Verde in September, 2000 (Tanré et al., 2003) and the Puerto Rico Dust Experiment (PRIDE) in June-July 2000 (Maring et al., 2003a). Collectively, these investigations have provided a wealth of information on the microphysical/optical properties of Saharan dust particles. Detailed comparison and contrast of these findings with the NAMMA observations are provided in Sect. 3 to 5 .

To serve its overarching science objective, NAMMA employed the NASA DC-8 aircraft instrumented with a variety of in-situ sensors to establish particle microphysical and optical properties, as well as a differential absorption lidar to determine the vertical distributions of water vapor, aerosol particles, and clouds (Ismail et al., 2010). The NAMMA sampling strategy involved a balanced mix of observations of AEWs and characterization of vertical distribution and properties of Saharan dust (Zipser et al., 2009). This strategy provided an optimal opportunity to observe how interactions between the SAL and AEW affected convective development. The primary objective of this paper is to provide high-quality, detailed information on dust vertical distributions and physical characteristics that can be used in further studies of dust impacts on SST, SAL self-heating, and cloud physics. In Sect. 2, we describe the measurement approach and instrument suite and then, in Sect. 3, provide a detailed analysis of the scattering and absorption coefficient comparisons between the direct measurements and spherical MieTheory calculations based on measured particle size distributions and reasonable assumptions of dust refractive indices, shape factor, and mass density. In Sect. 4, we summarize the overall microphysical/optical properties of the dust. Finally, in Sect. 5 we assess the vertical distribution of the Sahara dust layers as observed during the 33 soundings recorded during NAMMA.

\section{Observations}

\subsection{Measurements}

In-situ measurements of aerosol microphysical properties (number density, size distributions, and volatility) and optical parameters (scattering and absorption coefficients) were recorded aboard the NASA DC-8 aircraft using cabinmounted instruments that have been modified and characterized for use at reduced pressures (i.e., Thornhill et al., 2008). Sample air was provided to the instruments using a forwardfacing, window-mounted inlet probe. Real-time measurements of air speed, static pressure, and temperature were used to maintain isokinetic flow through the inlet tip to minimize inertial enhancement or depletion of coarse particles. Detailed measurements made during the spring 2003 DC-8 Inlet Characterization Experiment (DICE) showed that the inlet (labeled as UH inlet) has a $\sim 50 \%$ sampling efficiency at $5 \mu \mathrm{m}$ (dry aerodynamic diameter), which limits transmis- sion of the larger particles, e.g., dust and sea salt particles (Clarke et al., 2007; McNaughton et al., 2007).

A set of three TSI condensation particle counters (CPC) was used to obtain the number density of particles with diameters greater than $3 \mathrm{~nm}$ (ultrafine CPC, TSI-3025) and the nonvolatile and total number densities of particles with diameter greater than $10 \mathrm{~nm}$ ("hot" and "cold" CPCs, respectively) using two TSI-3010 instruments. Here, the difference between number densities from the TSI- 3025 and the TSI3010 represents the number density of ultrafine (with diameter between 3 and $10 \mathrm{~nm}$ ) particles. The hot CPC draws samples through a $40 \mathrm{~cm}$-long section of tubing heated to $300^{\circ} \mathrm{C}$ to evaporate volatile aerosol components (i.e., organics, nitrates, sulfate, etc.) and leave behind refractory particles such as soot, dust and sea salt. Post campaign tests suggest that the heated tube may cause a $30 \%$ particle loss (in number density) due to thermophoretic effects. Aerosol number densities are reported for ambient pressure and temperature conditions. In the absence of high ultrafine aerosol number densities, the estimated measurement precisions for the instruments are 5\% for the hot and cold CPCs and 10\% for the ultrafine CPC. The precisions are based on the uncertainties in the flow rate and temperature measurements.

Dry aerosol size distributions for the 0.07 to $1 \mu \mathrm{m}$ diameter range were measured with an Ultra-High Sensitivity Aerosol Spectrometer (UHSAS) manufactured by Droplet Measurement Technologies (Cai et al., 2008). The dry condition is defined here as relative humidity (RH) less than $30 \%$. Only data up to $0.6 \mu \mathrm{m}$ diameter were used due to instrument problems related to a reduced counting efficiency at the larger sizes during the NAMMA deployment. The UHSAS has 99 channel resolution and was calibrated before and periodically during the mission using latex spheres. The UHSAS was not operational for the second half of the NAMMA campaign. The aerodynamic size of particles in the 0.7 to $5 \mu \mathrm{m}$ (aerodynamic diameter) range was determined with a TSI model 3321 Aerodynamic Particle Sizer (APS). The upper size limit reflects the inlet size cut. The instrument was calibrated with both latex and silicon spheres; dust particle aerodynamic diameters were converted to geometric diameters using the dynamic shape factor and particle mass density as discussed in Sect. 3.

Aerosol scattering coefficients were measured at three wavelengths $(450,550$, and $700 \mathrm{~nm})$ under dry instrument condition (i.e., $\mathrm{RH}<30 \%$ ) with a TSI Integrating Nephelometer (model 3563), which integrates light scattered within a cylindrical sampling volume between $7^{\circ}$ and $170^{\circ}$. Values were corrected for size-dependent truncation errors using the methods derived by Anderson et al. (1996). Uncertainties were estimated for instrument noise, calibration, drift, and angular correction to $90 \%$ confidence following Anderson and Ogren (1998). The TSI nephelometers were calibrated using pure $\mathrm{CO}_{2}$ gas as a scattering medium. Particle absorption coefficients at three wavelengths (470, 532, and $660 \mathrm{~nm}$ ) were measured with a Radiance Research 

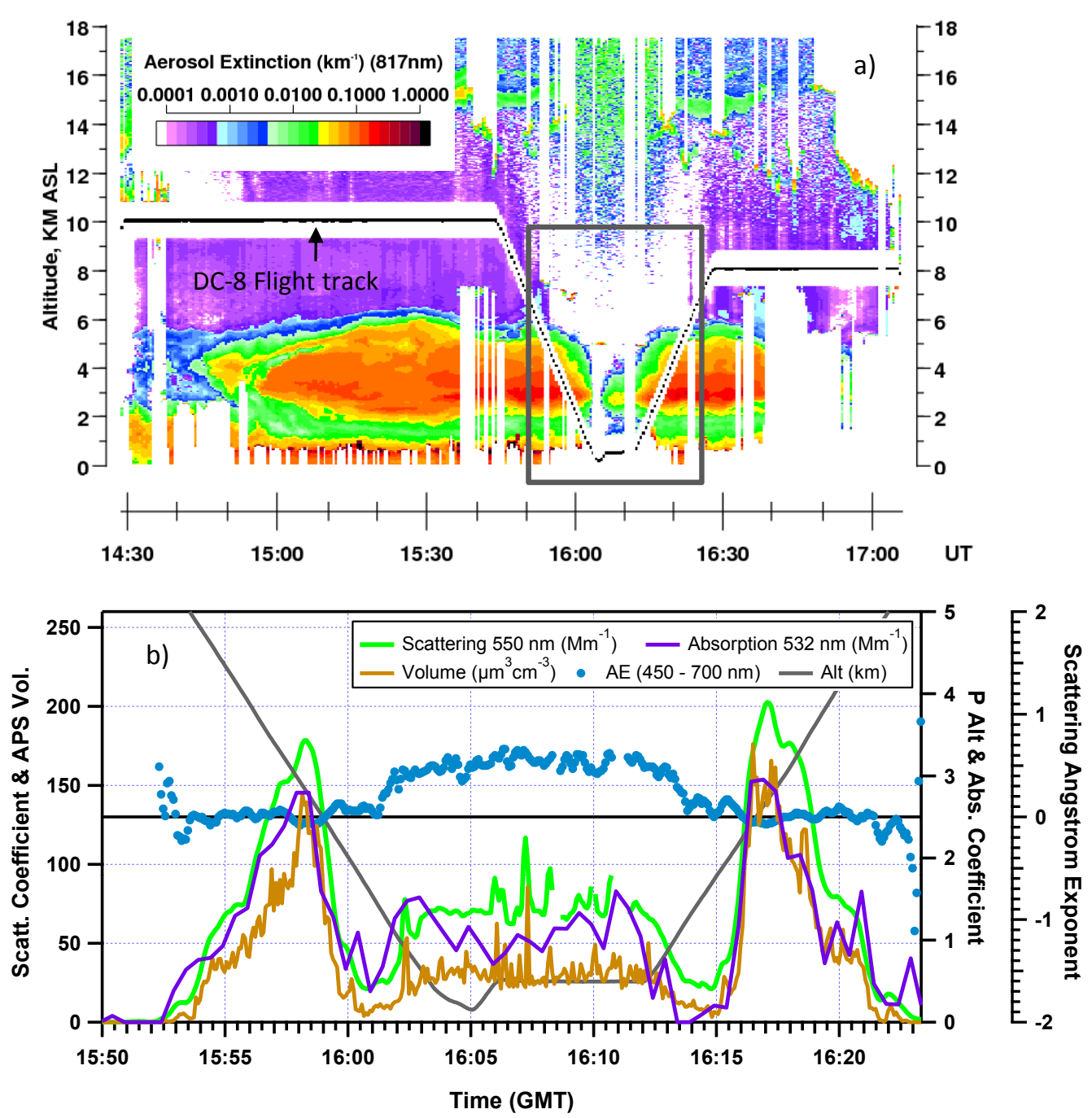

Fig. 2. (a) LASE (Lidar Atmospheric Sensing Experiment) vertical profiling data recorded on 20 August 2006 which identifies dust layer location (highly enhanced aerosol extinction) and b)time series plot of detailed microphysical and optical characterization (550 nm scattering and $532 \mathrm{~nm}$ absorption coefficients, scattering Ångström exponent, and coarse particle volume density) provided by NASA DC- 8 decent and ascent through the dust layer. The black frame in panel (a) shows the time limits plotted in panel (b).

Particle Soot Absorption Photometer (PSAP). The data were corrected for scattering by the filter media using the approach developed by Lack et al. (2008). The PSAP sample filters were heated to $40^{\circ} \mathrm{C}$ to decrease the $\mathrm{RH}$ and are thus considered to be representative of dry particles.

\subsection{Dust layer identification}

As discussed by Zipser et al. (2009), satellite observations indicate that the SAL was a persistent feature over the eastern North Atlantic during the NAMMA field campaign. We were thus able to use the DC-8 LASE (Lidar Atmospheric Sensing Experiment) observations to establish the dust layer vertical location, based on scattering properties of the SAL (Ismail et al., 2010), and use the onboard in-situ aerosol sensors to obtain dust microphysical and optical properties. Such a sampling approach is demonstrated in Fig. 2. From Fig. 2a, LASE vertical soundings along the flight track recorded in 20 August 2006 reveal an extensive dust layer marked by greatly enhanced extinction between $\sim 2$ and $5 \mathrm{~km}$. Ismail et al. (2010) showed that this dust layer was associated with the southern edge of the SAL and had propagated off the western coast of North Africa on 20 August 2006. HYSPLIT back-trajectories (Draxler and Rolph, 2010) along the center of the layer suggested that the dust particles were transported from the western part of the Saharan desert $(\sim 20$ $25^{\circ} \mathrm{N}$ and $\left.5-10^{\circ} \mathrm{W}\right) 40-70 \mathrm{~h}$ earlier. The data collected from NASA DC-8 vertical profiling of the dust layer at altitudes identified by the LASE observations (in Fig. 2b) shows dramatic increases in particle scattering coefficient at $550 \mathrm{~nm}$, 
$\sigma_{\mathrm{sp}}(550 \mathrm{~nm})$, absorption coefficient at $532 \mathrm{~nm}, \sigma_{\mathrm{ap}}(532 \mathrm{~nm})$, and integrated particle volume $(0.7-5 \mu \mathrm{m})$ density (measured by the APS instrument). The scattering Ångström exponent $\left(\AA_{\mathrm{sp}}\right)$, estimated for 450 to $700 \mathrm{~nm}$, decreases to near zero in this layer. It has been well documented that $\AA_{\text {sp }}$ is inversely related to particle size (e.g., Eck et al., 1999; Schuster et al., 2006 and reference therein) and that values less than one are indicative of particles dominated by sea-salt and/or dust (e.g., Schuster et al., 2006; Holben et al., 1991). Tanré et al. (2003) showed that the $\AA_{\text {sp }}$ values derived from Cape Verde AERONET observations were generally $<0.2$ during prevalent dust season, including August and September. Note that in Fig. 2b, the marine boundary layer (MBL) flight

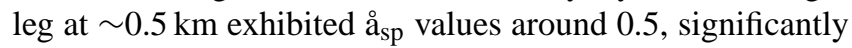
higher than those recorded within the dust layer. One may hypothesize that this $\stackrel{\circ}{s p}_{\text {difference is related to the particle }}$ type difference between dust and MBL aerosols. Transmission electron microscopy and energy dispersive X-ray spectrometry of collected particles larger than about $0.1 \mu \mathrm{m}$ in diameter showed that the predominant particle types in the SAL were Saharan dust, with typical dust containing silicon and aluminum, as well as smaller amounts of iron, potassium, calcium and magnesium. In the marine boundary layer, both sea-salt and primary dust, as well as dust mixed with soluble material such as sulfate and salts, were present (Table 1). Thus, we opt to limit the dust layer analysis to the free troposphere to effectively minimize the potential interference of sea-salt and processed dust. This is a reasonable assumption considering that strong temperature inversions were commonly observed at the top of MBL throughout the NAMMA sampling period (see detailed discussion in Sect. 5). The working criteria for dust layer identification are $(1) \sigma_{\mathrm{sp}}(550 \mathrm{~nm})$ significantly elevated above background, (2) $\stackrel{\circ}{s p}_{\text {sp }}(450-700 \mathrm{~nm}) \leq 0.2$, and (3) condensed water content $<0.01 \mathrm{~g} \mathrm{~m}^{-3}$ (the NAMMA DC-8 condensed water content measurement was provided by Twohy et al. (2009) using the counterflow virtual impactor instrument). Based on these criteria, a total of 62 dust layer encounters were identified from NAMMA observations. Five were over the Africa continent and the rest were over the northeastern Atlantic Ocean within the Atlantic MDR.

\section{Assessment of dust particle microphysical and optical measurements}

To establish confidence in characterization of the dust particle properties, it is essential to examine if consistency exists between the particle size distribution measurements and the optical property measurements. The observed size distributions can be used to calculate $\sigma_{\mathrm{sp}}(550 \mathrm{~nm})$ based on MieTheory for spherical particles. The calculated values can then be compared with direct observations from the nephelometer. A similar comparison can also be made with the
PSAP-derived absorption coefficients. Since all instruments shared a common sampling inlet, the scattering closure and absorption analysis provide a quantitative examination of consistency between our NAMMA size distribution and optical property measurements. A quantitative understanding of the scattering closure is essential to use NAMMA data for model assessment. In this study, scattering closure tests were performed on all identified NAMMA dust cases. The wavelengths chosen for these analyses were $550 \mathrm{~nm}$ for the scattering and $532 \mathrm{~nm}$ for absorption, which are in the middle of the solar visible range.

As described Sect. 2.1, the NAMMA particle size distribution observations were primarily constructed from measurements provided by the UHSAS and APS. The UHSAS instrument reports particle number concentration as a function of optical diameter, which closely approximates the geometric diameter. The APS data are in aerodynamic diameter, which must be converted to geometric size for Mie-Theory calculations. The size conversion factor (SCF), defined as the ratio of aerodynamic diameter to geometric diameter, is the square root of the particle density to shape factor ratio. Literature values for dust particle density range from 2.1 to $2.6 \mathrm{~g} \mathrm{~cm}^{-3}$, depending on composition (e.g., Reid et al., 2003, 2008). Recent studies of Saharan dust have used a value of $2.6 \mathrm{~g} \mathrm{~cm}^{-3}$ (e.g., McConnell et al., 2008, Schladitz et al., 2009), which is about $10 \%$ higher than values derived from earlier groundbased measurements (Maring et al., 2000). The shape factor is used to correct the non-spherical shape in the Stokes regime. Typical literature values for dust shape factor range from 1.2 to 2 (e.g., Reid et al., 2003, 2006). We opted to use the mid value of 1.6, which yields an SCF value of 1.27. This value is $10 \%$ lower than the value (i.e., 1.41) derived by Maring et al. (2000), which was used in a later study of Saharan dust by Reid et al. (2003). These latter investigators also noted that, because of its non-ideal flow characteristics, the APS is less efficient at sampling large dust particles. A more recent study by Reid et al. (2008) on Asian dust proposed modified values for the dust shape factor that account for the APS's non-Stokesian flow conditions. These recommended values range from 1.7 and 2.8 and are almost 50\% higher than the conventional shape factor values of 1.2 and 2 that are quoted above. The corresponding SCF values range from 1.21 to 0.94 , with a mid value of 1.04. In this study, we opt to test three SCF values, i.e., 1.04, 1.27, and 1.41, to assess the scattering closure.

The scattering (absorption) coefficient can be readily calculated by integrating the product of dust scattering (absorption) efficiency, particle geometric cross section, and number size distribution over the observed particle size range. The scattering (absorption) efficiency was estimated using MieTheory with spherical particle assumption (i.e., Bohren and Huffman, 1983) and refractive index values taken from previous studies. The reported values for the real part of the dust refractive index, $n_{r}$, are generally consistent and between 1.53 and 1.56 (Haywood et al., 2003; McConnell et 
Table 1. Particle types identified by electron microscopy/X-ray analysis ${ }^{1}$.

\begin{tabular}{lcrrrrrrrr}
\hline Sampling location & $\mathrm{n}^{2}$ & \multicolumn{3}{c}{ Size $^{3}(\mu \mathrm{m})$} & & Dust $^{4}$ & Salt $^{5}$ & Other $^{6}$ & Mixed $^{7}$ \\
\cline { 3 - 7 } Date & & Median & Mean & Range & $(\%)$ & $(\%)$ & $(\%)$ & $(\%)$ \\
\hline SAL Layer 1 & 107 & 0.30 & 0.48 & $0.09-4.23$ & 73 & 0 & 7 & 20 \\
5 September 2006 SAL Layer 2 & 100 & 0.54 & 0.74 & $0.11-5.26$ & 95 & 5 & 0 & 0 \\
5 September 2006 MBL 1 & 100 & 0.56 & 0.64 & $0.10-1.66$ & 7 & 19 & 9 & 65 \\
5 September 2001 MBL 2 & 100 & 0.41 & 0.50 & $0.09-1.42$ & 33 & 40 & 1 & 26 \\
26 August 2006 & & & & & & & & \\
\hline
\end{tabular}

${ }^{1}$ Data presented as particle number fractions of each type compared to the total population $(n)$.

2 Number of individual particles analyzed. Particles larger than approximately $0.1 \mu \mathrm{m}$ and $0.5 \mu \mathrm{m}$ were collected by impaction onto formvar-nickel grids downstream of a counterflow virtual impactor inlet with the counterflow turned off. Analysis was performed on a Philips CM12 transmission electron microscope with X-ray capability for elemental analysis.

Results from both size categories are combined here.

${ }^{3}$ Physical particle size, as the average of length + width as measured by the microscope.

${ }^{4}$ Dust: Silicates (rich in $\mathrm{Si}$, variable contributions from $\mathrm{Na}, \mathrm{Mg}, \mathrm{Al}, \mathrm{K}, \mathrm{Ca}$, and $\mathrm{Fe}$ ) and carbonates (rich in $\mathrm{Mg}$ and/or $\mathrm{Ca}$ with large $\mathrm{C}$ contribution).

5 Salt: Chlorides and sulfates of $\mathrm{Na}, \mathrm{K}, \mathrm{Ca}$ and $\mathrm{Mg}$.

${ }^{6}$ Other: Sulfates, industrial metals, or carbonaceous compounds.

7 Mixed: Combinations of $[3,4,5]$; for NAMMA, the most common mixture was dust mixed with sulfate, chloride, or salts

al., 2008; Osborne et al., 2008; Schladitz et al., 2009). In contrast, reported values for imaginary index, $n_{i}$, vary by as much as an order of magnitude (Schladitz et al., 2009). For example, DABEX observations yielded a Saharan dust $n_{i}$ of $0.0004 i$ (Osborne et al., 2008), whereas values of approximately $0.004 i$ were derived from SAMUM experiments (Haywood et al., 2003; Petzold et al., 2009; Schladitz et al., 2009). The variation of the $n_{i}$ values are attributed to its dependence on the dust iron oxide content, which naturally is a function of source region.

\subsection{Dust particle scattering closure assessment}

Figure 3a compares $\sigma_{\mathrm{sp}}(550 \mathrm{~nm})$ measured directly by a nephelometer with values calculated from observed size distributions using Mie-Theory. Each symbol represents one identified NAMMA dust layer encounter, while the solid circles and open squares correspond to $\sigma_{\mathrm{sp}}(550 \mathrm{~nm})$ values with and without corrections for nephelometer truncation errors, respectively. The $\mathrm{x}$-error bars represent one standard deviation calculated over the dust layer sampling and the y-error bars indicate the Mie-calculation uncertainties propagated from the size distribution standard deviations. In this case, the SCF was set to 1.27 , based on a dust particle density of $2.6 \mathrm{~g} \mathrm{~cm}^{-3}$ and a shape factor value of 1.6. This is regarded as the standard case in the closure analyses. The adopted value of $n_{r}$ is 1.53 , taken from the DODO experiment (McConnell et al., 2008), which was focused on Saharan dust and conducted in the same general time frame as NAMMA. The same value was also reported in an earlier work (SHADE) by Haywood et al. (2003). The value of $n_{i}$ was set to 0.0022 , derived from this study (see discussion in Sect. 3.2). As shown in Fig. 3a, both observed and calculated quantities are highly correlated with an $R^{2}$ value of 0.99 . This suggests that the variability in nephelometer observed scattering can be ex- plained by the variability observed in the size distribution. The linear orthogonal distance regression (ODR) slope for the truncation-corrected $\sigma_{\mathrm{sp}}(550 \mathrm{~nm})$ is $\sim 0.75$, which suggests either the Nephelometer had a high bias or the Miecalculation underestimated the $\sigma_{\mathrm{sp}}(550 \mathrm{~nm})$ due size distribution measurement biases, or a combination of both. An earlier ground-based scattering closure study showed a slope of 0.81 with an $R^{2}$ value of 0.99 (Maring et al., 2000). A more recent study suggested the Mie-Theory calculation may underestimate the scattering coefficient by $36 \%$ to $46 \%$, for a reasonable range of the refractive index values, at high dust concentration conditions (Schladitz et al., 2009). These field study results are corroborated by a laboratory intercomparison study which showed that TSI nephelometer observed supermicron particle scattering was about $30 \%$ higher than the values from Mie-Theory calculation (Heintzenberg et al., 2006). The failure of essentially all these independent assessments to achieve full closure raises some fundamental concerns which deserve further examination.

Studies have typically attributed the difference between observed and calculated dust particle scattering coefficients to one or a combination of three factors: (1) non-spherical particle effects on the Mie-Theory calculation (e.g., Schladitz et al., 2009), (2) nephelometer observational bias, possibly due to the truncation-error correction and/or other instrument limitations, and (3) APS undersizing of the particle size distribution (e.g., Anderson and Ogren, 1998; Maring et al., 2000; Heintzenberg et al., 2006).

Kalashnikova and Sokolik (2002) highlighted the significance of the dust particle shape impact on its optical properties, i.e., single scattering albedo $(\omega)$ and extinction coefficient $\left(\sigma_{\mathrm{ep}}\right)$. Using model simulations, these authors showed that the spherical assumption may lead to an underestimation in dust particle extinction up to $30 \%$. Recent work by Schladitz et al. (2009) showed that the non-spherical shape effect 

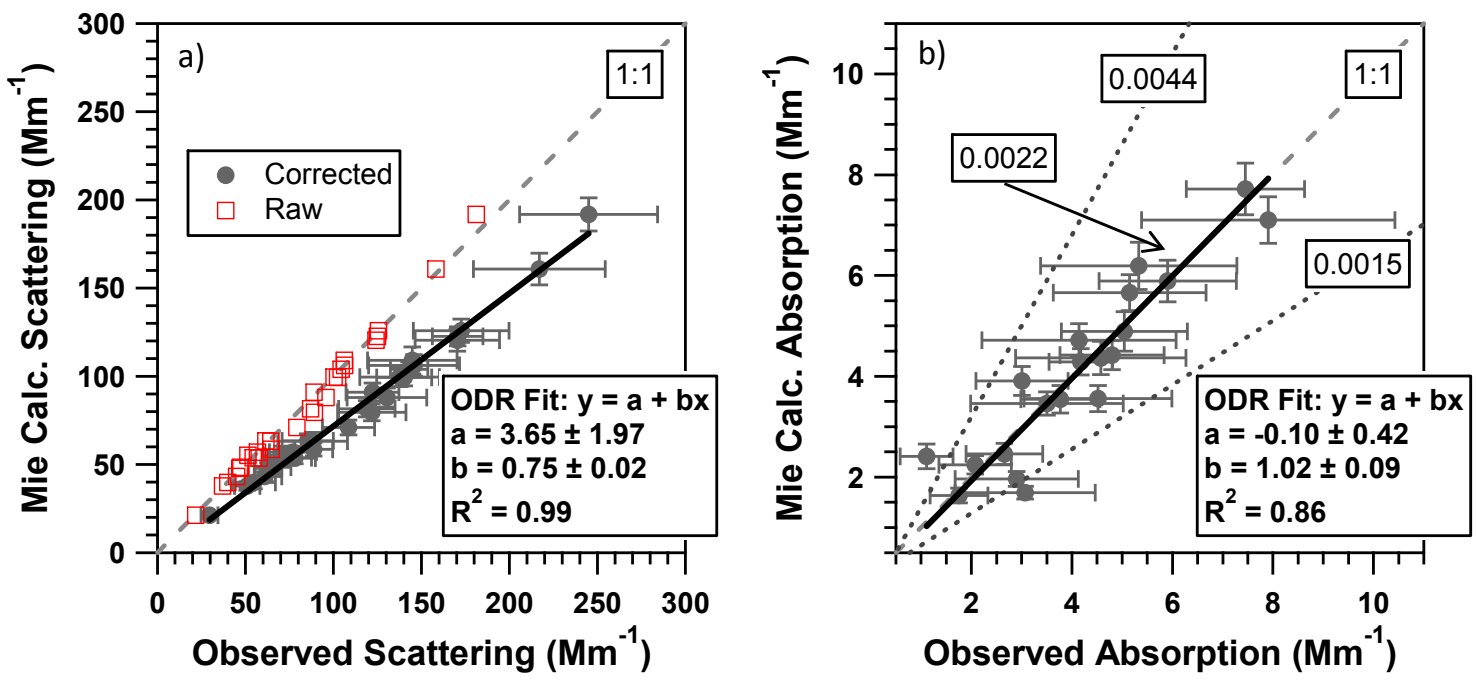

Fig. 3. (a) Scattering and (b) absorption closure assessment: direct observation vs. Mie-Theory calculation based on observed dust particle size distribution. Solid circles and open squares in (a) denotes data with and without Nephelometer truncation-error correction, respectively. Boxed values in panel (b) denote the $n_{i}$ values used in Mie-Theory calculations, represented by the dashed lines. The x-error bars represent one standard deviation calculated over the dust layer sampling and the y-error bars indicate the Mie-calculation uncertainties propagated from the size distribution standard deviations.

is around $16 \%$ at $550 \mathrm{~nm}$ and further suggested that the discrepancy in their scattering closure might be accounted for, at least to a large extent, by the non-spherical shapes of the supermicron particles. Other modeling studies have suggested a much smaller impact (e.g., Liu et al., 2002; Quirantes et al., 2008). The difference between these earlier works is likely due to their own assumptions of particle shapes and size distributions. Using the NAMMA size distribution data described in this paper and T-Matrix calculations, Omar et al. (2010) estimated the extinction-to-backscatter ratio of dust aerosols using a spheroidal assumption for the particle shape. These calculations showed at most a $7 \%$ difference between the spherical and spheroidal scattering coefficients.

Regarding possible errors in the direct scattering measurements, Heinzenberg et al. (2006) compared 10 identical TSI nephelometers and found that their output signals agreed to better than $7 \%$ when sampling ambient aerosols. More detailed laboratory tests yielded a $6 \%$ average difference from the ensemble average with a range of from 2 to $11 \%$ for the submicron particles; results varied from 5 to $29 \%$, averaging at $13 \%$ for supermicron particles. While these tests provided encouraging results, the scattering closure for the supermicron DEHS (di-ethylhexyl-sebacate) particles revealed that the observed scattering coefficients were about $30 \%$ higher than values calculated from APS size distributions (Heinzenberg et al., 2006). Using model simulations, these authors also showed that the nephelometer truncation loss is a strong function of particle size. The estimated truncation-correction for TSI nephelometer increased from $<10 \%$ for particles $<0.5 \mu \mathrm{m}$ to over $50 \%$ for particle size $>5 \mu \mathrm{m}$. The truncation-correction has been typically made using the algorithm developed by Anderson and Ogren (1998). This correction is based on the bulk Ångström exponent. Quirantes et al. (2008) argued that this type of correction is not appropriate, especially for large particles. Their model simulation showed the correction factor becomes ambiguous (or multi-valued) when the Ångström exponent approaches zero, as it often does when a significant fraction of the scattering arises from supermicron particles. These authors developed a new truncation-correction based on the effective size parameter and the width of the size distribution, both of which can be derived from the observed size distributions. Two NAMMA test cases were picked for the identified dust layer encounters. The estimated truncation factors for $550 \mathrm{~nm}$ using Quirantes et al. (2008) correction scheme is found to be $\sim 30 \%$ lower than those based on Anderson and Ogren (1998). Laboratory tests should be performed to further evaluate this new truncation correction scheme, especially for the supermicron particles. Finally, it should be noted that Fig. 3a shows nearly perfect agreement between the Mie-Theory calculation and raw nephelometer data (without Anderson and Ogren truncation-correction). The latter is about consistently $27 \%$ lower than $\sigma_{\mathrm{sp}}(550 \mathrm{~nm})$.

The potential APS undersizing problem has been widely discussed in the literature. Reid et al. (2008) provided an extensive review and stated that the APS may undersize dustlike particles by 10 to $30 \%$. Interestingly, Heintzenberg et al. (2006) showed that a $20 \%$ adjustment for APS undersizing bias would raise the Mie-Theory calculated values about $5 \%$ higher than the nephelometer observations. In this study, a similar level of closure would be achieved if the SCF value were decreased to 1.04 . This value corresponds to a dust 
particle density value of 2.6 and a shape factor of 2.3. The latter is the midpoint of the range of non-Stokesian shape factors derived by Reid et al. (2008) for Southwest Asian dust. On the other hand, if the size conversion factor (i.e., 1.41) used by Maring et al. (2000) were adopted, the calculated $\sigma_{\mathrm{sp}}(550 \mathrm{~nm})$ would be $\sim 36 \%$ lower than the direct measurements. For all three cases with different SCF values, the $R^{2}$ values remains at 0.99 . Again this establishes the high levels of correspondence between the observed $\sigma_{\mathrm{sp}}(550 \mathrm{~nm})$ and the observed particle number size distribution. Moreover, the level of scattering closure is very sensitive to the SCF value. Additional constraint on the SCF value would require a dust mass measurement which can be used for an independent assessment of mass closure. This may be of particular significance given that the performance of individual APS instruments may vary considerably and it is difficult to experimentally and quantitatively determine the magnitude of APS undersizing. At the same time it should also be recognized that the irregular shapes of the dust particles make the definition of particle size ambiguous. Thus, the APS undersizing issue must be linked to how well the geometric size represents the effective cross section or equal-projected-area for dust particles. Finally, we note that the closure tests are unsuitable for examining the reasonableness of the UHSAS measurement (responsible for part of fine particle sizing) since its size range contributes less than $20 \%$ of the total scattering.

\subsection{Dust particle absorption assessment}

The results of the absorption comparison is displayed in Fig. $3 \mathrm{~b}$ as a scatter plot of observed versus calculated green absorption coefficients, i.e., $\sigma_{\mathrm{ap}}(532 \mathrm{~nm})$. The solid circle symbols in Fig. $3 \mathrm{~b}$ were based on $n_{i}$ value of 0.0022 , which was adjusted to best reproduce the observations. The solid line represents the linear ODR fit of the solid circles and two additional dotted lines are ODR fit lines corresponding to $n_{i}$ values of 0.0015 and 0.0044 . Like in the scattering closure analysis, the calculated $\sigma_{\mathrm{ap}}(532 \mathrm{~nm})$ is highly correlated with the observed value with an $R^{2}$ value of 0.86 . This again strengthens our confidence in the size distribution measurements that the observed size distribution variability is highly consistent with that in absorption measurements. Given the results displayed in Fig. 3b, one would conclude the best $n_{i}$ estimate is 0.0022 for NAMMA airborne observations. Within the combined observational uncertainty and ambient variability, $n_{i}$ estimates fall between 0.0015 and 0.0044 . This range is in good agreement with the values reported in recent field studies, i.e., SHADE, DODO, and SAMUM (Haywood et al., 2003; McConnell et al., 2008; Schladitz et al., 2009) as well as some reported values derived from AERONET observations (e.g., Tanré et al., 2003).

Note that in Fig. 3b, the x-error bars represent the standard deviation of the observed values while the y-error bars correspond to the calculated uncertainties propagated from the particle number size distribution uncertainties. The larger $\mathrm{x}$ -

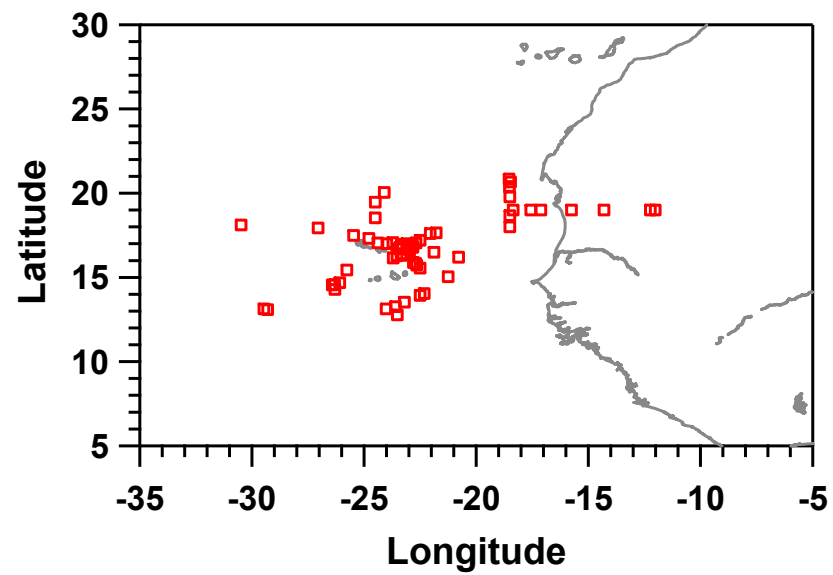

Fig. 4. Geographic location of the 62 NAMMA dust layer encounters.

error bars reflect both ambient variability and lowered measurement precision at these low absorption levels. The data points displayed in the plot are restricted to those with signal to noise ratio values (i.e., the average divided by the standard deviation) $>2$. Lack et al. (2008) stated that the PSAP's accuracy is limited to $20-30 \%$, primarily because its data is subjected to empirical corrections for filter transmission and scattering. Virkkula et al. (2005) showed that the scattering correction factor for high scattering particles ranges from 0.011 to 0.023 . In the case of NAMMA absorption measurements, this range represents an average uncertainty of $28 \%$. For the lowest $\sigma_{\text {ap }}(532 \mathrm{~nm})$ values (i.e., between 0.5 $1 \mathrm{Mm}^{-1}$ ), the uncertainty can reach nearly $100 \%$. Because of the PSAP measurement uncertainties and the absorption dependence on actual dust particle composition, the absorption closure is not as robust as the scattering closure analysis.

\section{Saharan dust optical and microphysical properties observed in NAMMA}

The above scattering closure test and absorption comparison indicate that the NAMMA particle size distribution measurements are quantitatively related to the $\sigma_{\mathrm{sp}}(550 \mathrm{~nm})$ and $\sigma_{\mathrm{ap}}(532 \mathrm{~nm})$ in terms of variability. The systematic discrepancy found in the scattering closure may be explained by a combination of instrumental and particle microphysical uncertainties. Thus, we believe that NAMMA observations can provide a consistent and reasonably accurate characterization of the optical and microphysical properties of the Saharan dust particles. The discussion that follows contrasts the characteristics of the Saharan dust with those of background aerosols within the same altitude regime outside the influence of SAL.

Figure 4 illustrates the sampling locations of the 62 dust layer encounters, which were mostly in the east portion of the MDR, an area where tropical storms are frequently spawned 
Table 2. Summary of NAMMA dust layer met parameters*.

\begin{tabular}{llrrrrr}
\hline & Alt $(\mathrm{km})$ & $T(\mathrm{k})$ & $\mathrm{RH}$ & $U\left(\mathrm{~m} \mathrm{~s}^{-1}\right)$ & $V\left(\mathrm{~m} \mathrm{~s}^{-1}\right)$ \\
\hline Dust & Average & 2.50 & 287 & $48 \%$ & -11.3 & 0.4 \\
Layer & Std. Deviation & 0.90 & 7 & $16 \%$ & 7.3 & 4.5 \\
& Median & 2.27 & 288 & $49 \%$ & -10.8 & 0.6 \\
& 10th percentile & 1.52 & 278 & $25 \%$ & -20.8 & -4.4 \\
& 90th percentile & 3.69 & 295 & $69 \%$ & -3.0 & 4.2 \\
\hline \multirow{2}{*}{ Back- } & Average & 2.67 & 284 & $70 \%$ & -4.7 & 2.7 \\
ground & Std. Deviation & 0.71 & 5 & $21 \%$ & 8.1 & 7.3 \\
& Median & 3.03 & 283 & $74 \%$ & -4.5 & 1.9 \\
& 10th percentile & 1.53 & 279 & $36 \%$ & -15.7 & -5.2 \\
& 90th percentile & 3.29 & 291 & $94 \%$ & 6.5 & 11.0 \\
\hline
\end{tabular}

* Alt = sampling altitude, $T=$ static temperature, $\mathrm{RH}=$ relative humidity, $U=$ eastward/westward wind speed component, East is positive, $V=$ northward/southward wind speed component, North is positive.

Table 3. Summary of microphysical parameters* for NAMMA dust layers and background.

\begin{tabular}{llrrrrrr}
\hline & & $\begin{array}{r}\mathrm{N}_{>10 \mathrm{~nm}} \\
\left(\mathrm{~cm}^{-3}\right)\end{array}$ & $\begin{array}{r}N_{>1 \mu \mathrm{m}} \\
\left(\mathrm{cm}^{-3}\right)\end{array}$ & nvf & $\begin{array}{r}S \\
\left(\mu \mathrm{m}^{2} \mathrm{~cm}^{-3}\right)\end{array}$ & $\begin{array}{r}\text { Vol } \\
\left(\mu \mathrm{m}^{3} \mathrm{~cm}^{-3}\right)\end{array}$ & $\begin{array}{r}\text { VMD } \\
(\mu \mathrm{m})\end{array}$ \\
\hline Dust & Average & 350 & 13 & $70 \%$ & 168 & 45 & 2.07 \\
Layer & Std. Deviation & 78 & 5 & $6 \%$ & 76 & 22 & 0.20 \\
& Median & 334 & 13 & $71 \%$ & 166 & 44 & 2.09 \\
& 10th percentile & 268 & 7 & $62 \%$ & 86 & 20 & 1.83 \\
& 90th percentile & 461 & 22 & $77 \%$ & 299 & 79 & 2.31 \\
\hline \multirow{2}{*}{ Back- } & Average & 355 & 2 & $45 \%$ & 21 & 3.4 & 0.88 \\
ground & Std. Deviation & 403 & 3 & $26 \%$ & 27 & 5.8 & 0.55 \\
& Median & 275 & 0.1 & $53 \%$ & 9.7 & 0.8 & 0.87 \\
& 10th percentile & 136 & 0 & $7 \%$ & 0.3 & 0.0 & 0.21 \\
& 90th percentile & 626 & 5 & $74 \%$ & 50 & 9.0 & 1.56 \\
\hline
\end{tabular}

$* \mathrm{~N}_{>10 \mathrm{~nm}}=$ number density for particle diameters lager than $10 \mathrm{~nm}, N_{>1 \mu \mathrm{m}}=$ number density for particle diameters lager than $10 \mu \mathrm{m}, \mathrm{nvf}=$ non-volatile number fraction, $S=$ surface area density, $\mathrm{Vol}=$ volume density, $\mathrm{VMD}=$ volume median diameter.

and undergo cyclogenesis. Table 2 presents relevant statistics to describe the meteorological conditions that existed within the dust layers as identified by NAMMA in-situ observations; it also includes statistics for background aerosols sampled in the same altitude regimes outside the dust impacted regions. The center of the observed NAMMA dust layers ranged between 1.5 and $3.7 \mathrm{~km}$ in altitude. The average air temperature was $287 \pm 7 \mathrm{~K}$ for the dust layers, which is $3 \mathrm{~K}$ higher than the average background temperature. Again, background is defined here as the region within the same altitudes outside the SAL. Comparison of the RH suggests that the average SAL RH was $48 \pm 16 \%$, significantly lower than the background value of $70 \pm 21 \%$. The observed temperature and $\mathrm{RH}$ are generally consistent with previous studies which indicate that dust layers were associated with the SAL. The higher RH value (e.g., approximately 70\%) dust cases were encountered near the edge of SAL or where the SAL was impinging on convectively active regions. Finally, the NASA
DC-8 wind measurements showed a much stronger average easterly wind within the dust layers than typical ambient conditions, -11.3 compared to $-4.7 \mathrm{~m} \mathrm{~s}^{-1}$.

Table 3 shows statistics for several key particle microphysical properties for the dust layers and background air. The average number density of particles with diameters larger than $10 \mathrm{~nm}, N_{>10 \mathrm{~nm}}$, is about the same for the dust layers and background. The standard deviation for the dust layer is over a factor of 5 smaller than the background value, which suggests the dust layers have a much narrower range of variation. The $N_{>10 \mathrm{~nm}}$ value for dust layer ranges from 268 to $461 \mathrm{~cm}^{-3}$ (10th and 90th percentiles), with a median value of $334 \mathrm{~cm}^{-3}$. For the supermicron particles, the number density, $N_{>1 \text { um }}$, is much higher for the dust layers with an average at $13 \mathrm{~cm}^{-3}$, in contrast to $2 \mathrm{~cm}^{-3}$ for background. For dust layers, $N_{>1 \mu \mathrm{m}}$ constitute about $3.5 \%$ of $N_{>10 \mathrm{~nm}}$. Also displayed in Table 3 is the non-volatile fraction (nvf) of particles derived from the ratio of heated (to $300^{\circ} \mathrm{C}$ ) and 
unheated particle number density measurements. On average, $70 \pm 6 \%$ of dust layer particles are non-volatile. Considering the potential $30 \%$ particle loss for the heated $\mathrm{CN}$ counter (see Sect. 2.1), the dust nvf value can potentially be well over $90 \%$. This suggests dust layers are consistently composed primarily of non-volatile particles, even in the submicron modes. For the background, the average nvf value is at $45 \pm 26 \%$. The difference in integrated surface and volume densities, $S$ and Vol, are as dramatic as the contrast in $N_{>1 \mu \mathrm{m}}$ values. The elevated $S$ and Vol values can directly be attributed to the contribution from the coarse mode particles. This is further discussed in the context of size distributions in the text that follows.

Figure 5 displays the observed particle number and volume size distributions for three individual dust layers representing the integrated volume density values at the median, 10th, and 90th percentiles (given in Table 3). The open and solid circles represent the UHSAS and APS measurements, respectively. The value of the volume density integrated over the open and solid circles corresponds to the median NAMMA dust layer Vol (see Table 3). The curve V50 is the tri-modal lognormal fit for the open and solid circles and curve V10 and V90 are the fit lines for dust layers corresponding to the 10th and 90th percentile of the dust volume densities (also in Table 3), respectively. The tri-modal lognormal parameters are given in Table 4 for the number size distribution curve fits. The particle size is shown in geometric diameter and the standard case SCF value of 1.27 is used here for converting APS aerodynamic diameter to geometric diameter. With the various choices of the shape factor and dust particle density, the SCF has a considerable range of possible values. Therefore, the coarse particle size shown in Fig. 5a and 5b is inherently uncertain due to its dependence on SCF. At the same time, the closure tests have shown, within a wide range of SCF values, the high degree of correlation between the particle size distribution and scattering measurements. Furthermore, a high level of quantitative closure was obtained between these two independent measurements. Thus, Fig. 5a and $5 \mathrm{~b}$ can be considered as reasonable representations of the Saharan dust particle size distributions, provided the impact of the $4 \mu \mathrm{m}$ sampling inlet size cut is limited.

Figure 5a and Table 4 suggest that the observed dust layer number size distribution can be reasonably well represented by a tri-modal lognormal curve. In the submicron portion, all three curves have two modes around 0.1 and $0.6 \mu \mathrm{m}$. The curve V90, however, has a significantly larger mode at $1.56 \mu \mathrm{m}$. The $N_{>1 \mu \mathrm{m}}$ value associated with $\mathrm{V} 90$ is $23 \mathrm{~cm}^{-3}$, a factor of 1.7 and 3.4 higher than those of V50 and V10, respectively. For all 62 observed dust layers, the supermicron particles contribute an average of $88 \pm 2 \%$ to the total volume density and $66 \pm 4 \%$ to the total surface area density, $S$. Thus the sharp contrast in $S$ and Vol shown in Table 3 is consistent with the differences between the dust layer and background $N_{>1 \mu \mathrm{m}}$. Finally, it is interesting to note that the
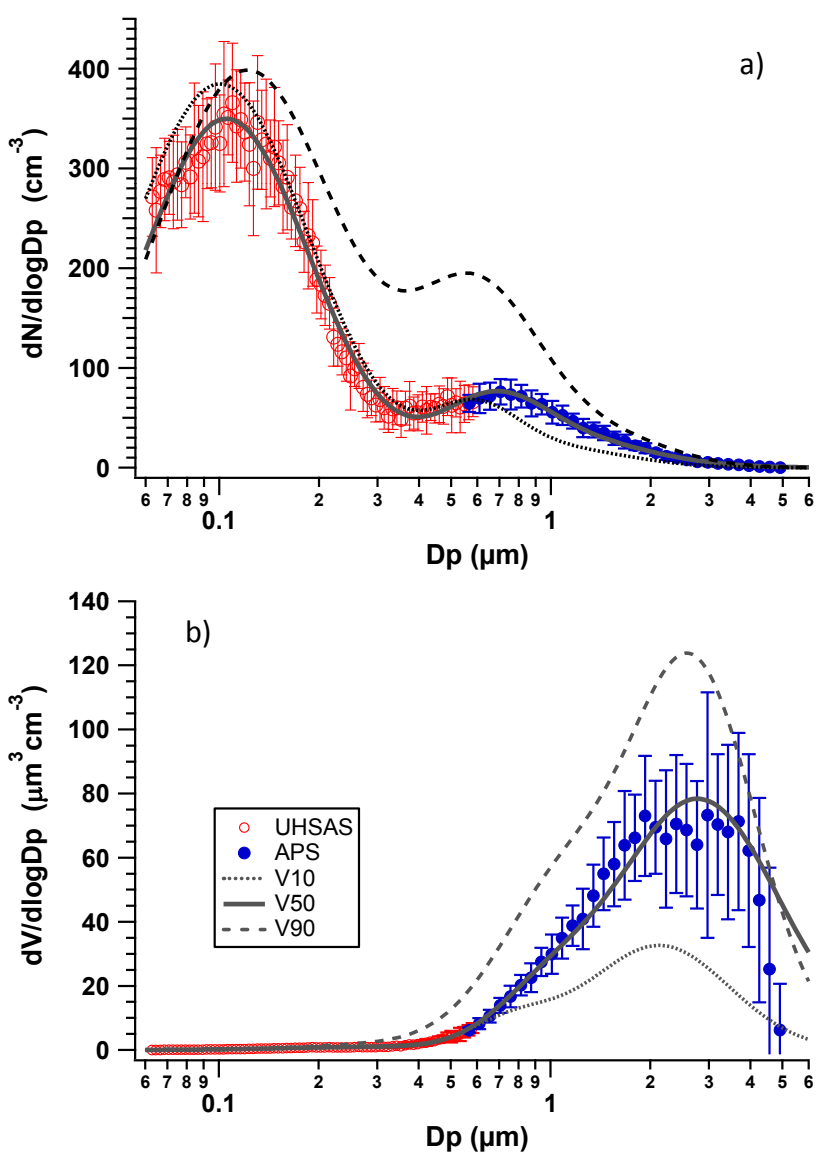

Fig. 5. Observed Saharan dust (a) particle number and (b) volume size distributions. Particle size is given in geometric diameter. Open and solid symbols denote UHSAS and APS observations, respectively. Error bars represent one standard deviation estimated during the dust layer sampling period. Curve V10, V50, V90 are tri-modal lognormal fits of the size distributions for the volume density values corresponding to 10 th, 50 th, and 90 th percentiles.

largest difference in number size distribution between curve V90 and curves V50 and V10 is in the submicron mode, especially between $\sim 0.3$ and $1 \mu \mathrm{m}$. Similar features are also seen for several other dust layers with the high Vol values. This size range has limited contribution to the total integrated volume density (see Fig. 5b), but may have significant impact on cloud formation and cloud properties because of the much high number density. We believe it is important for future studies to verify the NAMMA observation and to examine the potential impact of submicron-sized dust on regional $\mathrm{CCN}$ budgets.

Not surprisingly, Table 3 shows that the volume median diameter (VMD) for the SAL is a factor 2.4 larger than that of background air, which is attributable to the preponderance of coarse particles residing within these relatively fresh dust plumes and easily accounts for the average difference seen in Vol and, to a much lesser extent, in $S$. However, the NAMMA average dust VMD is almost a factor of 2 lower 
Table 4. Tri-modal lognormal parameters* for NAMMA size distribution $(0.6-6 \mu \mathrm{m})$.

\begin{tabular}{lrrrrrrrrr}
\hline & $N_{1}$ & $\sigma_{1}$ & $D_{1}$ & $N_{2}$ & $\sigma_{2}$ & $D_{2}$ & $N_{3}$ & $\sigma_{3}$ & $D_{3}$ \\
\hline 10th percentile & 591 & 1.85 & 0.10 & 40.8 & 1.36 & 0.58 & 22.6 & 1.62 & 1.05 \\
SD (V10) & & & & & & & & & \\
$\begin{array}{l}\text { Median SD } \\
\text { (V50) }\end{array}$ & 506 & 1.78 & 0.11 & 50.8 & 1.44 & 0.66 & 38.6 & 1.75 & 1.10 \\
$\begin{array}{l}\text { 90th percentile } \\
\text { SD (V90) }\end{array}$ & 620 & 1.86 & 0.12 & 198 & 1.56 & 0.60 & 27.6 & 1.54 & 1.56 \\
\hline
\end{tabular}

$* \frac{d N}{d \log D}=\sum_{i=1}^{3} \frac{N_{i}}{\sqrt{2 \pi} \ln \sigma_{i}} \exp \left(-\frac{\left(\ln D-\ln D_{i}\right)^{2}}{2 \ln ^{2} \sigma_{i}}\right)$.

than values derived from other recent studies, which also used APS measurements. For example, Maring et al. (2003b) reported a VMD value of $3.6 \mu \mathrm{m}$ from the PRIDE airborne observations. An even higher value of $4.3 \mu \mathrm{m}$ was measured in a ground-based experiment (Maring et al., 2003b). It is noted that NAMMA and these earlier studies all used APS for the coarse mode particle measurement. The smaller NAMMA VMD value is at least partially due to the aerosol inlet having lower transmission efficiency for dust particles larger than $\sim 4 \mu \mathrm{m}$ (see discussion in Sect. 2.1). This effect can be seen clearly in Fig. $5 \mathrm{~b}$ as $d V / d \log D p$ value has a sharp decrease starting at $D p>4 \mu \mathrm{m}$.

In addition to comparison with other in-situ measurements, the NAMMA airborne dust particle size distribution is assessed using the effective radius, $r_{\text {eff }}$, from the version MODIS aerosol products. The MODIS $r_{\text {eff }}$ retrieval is based on the algorithm developed by Tanré et al. (1997). Figure 6 shows a direct comparison for the 30 co-located cases (within $0.25^{\circ}$ ) between the MODIS retrieved $r_{\text {eff }}$ and the values derived from the NAMMA observations. This comparison shows the average MODIS to NAMMA DC- 8 ratio is $1.15 \pm 0.15$, ranging from 0.97 to 1.31 . This range is well within the uncertainties. The uncertainty associated MODIS value is estimated to be $25 \%$ (Remer et al., 2002). The DC- 8 $r_{\text {eff }}$ uncertainty value is $\sim 35 \%$, propagated from the overall uncertainties in $S$ and Vol. This close agreement is rather interesting because the MODIS estimate is based on a column average while the DC- 8 may have sampled only one of the dust layers within the vertical column. As discussed in Sect. 5 below, the vertical distribution of Saharan dust particles is often complicated, involving multiple overlapping layers over the eastern North Atlantic. The DC-8 sampling altitude ranged from 1.6 to $3.8 \mathrm{~km}$ for the dust layers involved in this comparison. The average DC- $8 r_{\text {eff }}$ is $0.80 \pm 0.07$, suggesting that the dust layer $r_{\text {eff }}$ may not be a strong function of altitude and the dust particle size distribution is reasonably constant for layers at various altitudes. This hypothesis is further strengthened by the agreement between the MODIS retrieved column $r_{\text {eff }}$ average and in-situ observations.

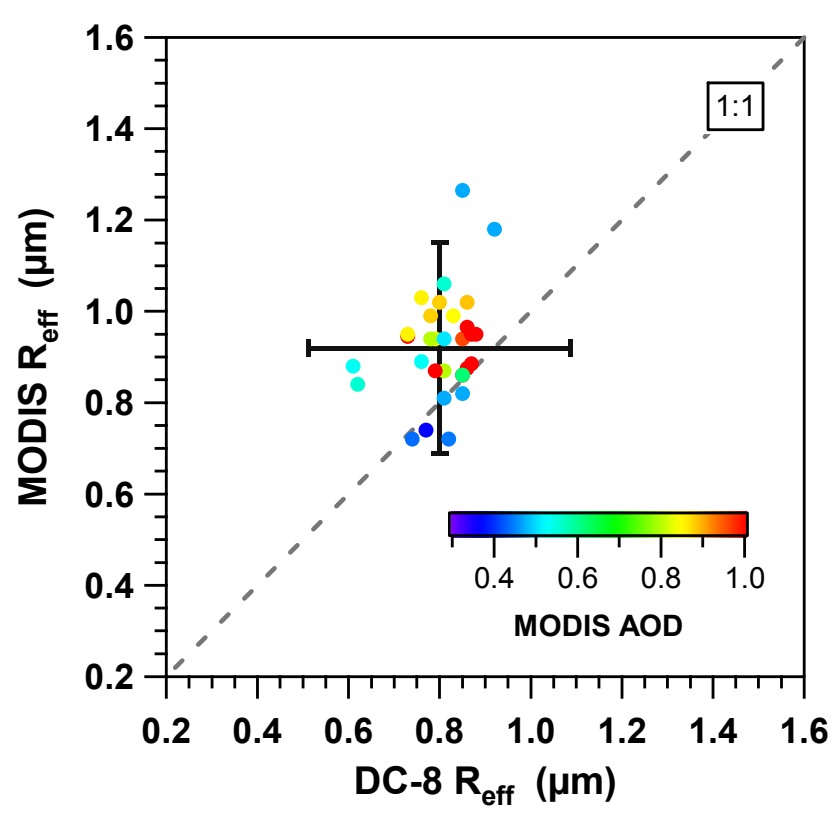

Fig. 6. Comparison of MODIS retrieved particle effective radius with the values derived from NASA DC-8 in-situ measurement size distribution for 30 co-located encounters. Error bars represent the estimated uncertainties.

It is worth noting that the VMD range is fairly small (the standard deviation $<10 \%$ of the average) even though the dust layer sampling region extended out $2000 \mathrm{~km}$ from the source regions. This suggests that the dust particle size distribution remained reasonably constant during the westward transport. This phenomenon was noted by Maring et al. (2003b) and was supported by the later observations by Liu et al. (2008), and Reid et al. (2008). Based on model simulations, Maring et al. (2003b) showed that the Stokes gravitational settling of dust particles might be offset by a slight upward atmospheric motion of $\sim 0.33 \mathrm{~cm} \mathrm{~s}^{-1}$. As discussed earlier, NAMMA observations showed that the SAL is significantly warmer $(\sim 3 \mathrm{~K})$ than the surrounding air and that the vertical velocity measurements suggest the dust layers were in uplifting regions. These findings are generally consistent with the hypothesis of Maring et al. (2003b). 
Table 5. Summary of optical parameters* for NAMMA dust layers and background.

\begin{tabular}{llrrrrrrr}
\hline & & $\begin{array}{r}\sigma_{\mathrm{sp}}(550 \mathrm{~nm}) \\
\left(\mathrm{Mm}^{-1}\right)\end{array}$ & $\begin{array}{r}\sigma_{\mathrm{ap}}(532 \mathrm{~nm}) \\
\left(\mathrm{Mm}^{-1}\right)\end{array}$ & åsp $_{\text {sp }}$ & å $_{\text {ap }}$ & $\omega_{470 \mathrm{~nm}}$ & $\omega_{532 \mathrm{~nm}}$ & $\omega_{670 \mathrm{~nm}}$ \\
\hline Dust & Average & 141 & 5.2 & 0.009 & 4.13 & 0.95 & 0.97 & 0.99 \\
Layer & Std. Deviation & 63 & 2.5 & 0.083 & 0.47 & 0.01 & 0.01 & 0.00 \\
& Median & 138 & 4.9 & -0.023 & 4.13 & 0.95 & 0.97 & 0.99 \\
& 10th percentile & 66 & 2.4 & -0.075 & 3.66 & 0.94 & 0.96 & 0.98 \\
& 90th percentile & 244 & 8.0 & 0.140 & 4.67 & 0.96 & 0.97 & 0.99 \\
\hline Back- & Average & 29 & 2.3 & 0.733 & 2.81 & 0.89 & 0.91 & 0.92 \\
ground & Std. Deviation & 42 & 2.0 & 0.793 & 1.31 & 0.12 & 0.12 & 0.13 \\
& Median & 9.6 & 1.6 & 0.440 & 2.85 & 0.93 & 0.95 & 0.97 \\
& 10th percentile & 0.8 & 0.6 & 0.047 & 1.08 & 0.76 & 0.74 & 0.71 \\
& 90th percentile & 87 & 5.2 & 1.93 & 4.61 & 0.97 & 0.98 & 0.99 \\
\hline
\end{tabular}

* $\sigma_{\mathrm{sp}}(550 \mathrm{~nm})=$ scattering coefficient at $550 \mathrm{~nm}, \sigma_{\mathrm{sp}}(550 \mathrm{~nm})=$ absorption coefficient at $532 \mathrm{~nm}$, åsp = scattering Angstrom exponent, åap $=$ absorption Angstrom exponent, $\omega_{470 \mathrm{~nm}}=$ single scattering albedo at $470 \mathrm{~nm}, \omega_{532 \mathrm{~nm}}=$ single scattering albedo at $532 \mathrm{~nm}, \omega_{670 \mathrm{~nm}}=$ single scattering albedo at $670 \mathrm{~nm}$.

Table 5 provides a statistical summary of the observed optical properties for both Saharan dust layers and the background conditions. The median dust layer $\sigma_{\mathrm{sp}}(550 \mathrm{~nm})$ and $\sigma_{\mathrm{ap}}(532 \mathrm{~nm})$ are factors of 14 and 3 higher than background, respectively. These differences are similar to those in some of the microphysical properties, i.e., $N_{>1 \mu \mathrm{m}}, S$, and Vol. Figure 7 a shows that both dust layer $\sigma_{\mathrm{sp}}(550 \mathrm{~nm})$ and $\sigma_{\text {ap }}(532 \mathrm{~nm})$ are highly correlated with the volume density with $R^{2}$ values of 0.98 and 0.81 , respectively. These correlations suggest that the high levels of scattering and absorption are driven by the dust particle volume loading. Assuming a density of $2.6 \mathrm{~g} \mathrm{~cm}^{-3}$, the mass extinction efficiency, MEE, at $532 \mathrm{~nm}$ is estimated at $1.09 \mathrm{~m}^{2} \mathrm{~g}^{-1}$ for the dust particles. The uncertainty for this estimate can be as high as $40 \%$ due to the potential uncertainties in the scattering and volume density measurements. The low inlet sampling efficiency for particles larger than $\sim 4 \mu \mathrm{m}$ may result in a low bias in mass estimate and high bias in MEE. The NAMMA airborne MEE assessment is, however, well within the range of the values reported by the NAMMA ground based studies: i.e., $1.23 \pm 0.71$ and $0.93 \pm 0.17 \mathrm{~m}^{2} \mathrm{~g}^{-1}$ (Jeong et al., 2008), which was capable of measuring particles larger than $10 \mu \mathrm{m}$. The NAMMA airborne MEE estimate is also highly consistent with the value of $1.14 \mathrm{~m}^{2} \mathrm{~g}^{-1}$ by McConnell et al. (2008) derived from the other AMMA airborne study. Maring et al. (2000), however, reported a significantly lower value of $0.50 \mathrm{~m}^{2} \mathrm{~g}^{-1}$ for the mass scattering efficiency, which is very close to MEE for dust because of very low contribution of absorption to dust extinction. The lower NAMMA MEE value can partially attributed to the low sampling efficiency for particles larger than $\sim 4 \mu \mathrm{m}$. Finally, as shown in Fig. $7 \mathrm{~b}$, the dust layer $\sigma_{\mathrm{sp}}(550 \mathrm{~nm})$ and $\sigma_{\mathrm{ap}}(532 \mathrm{~nm})$ both have strong correlation with $N_{>1 \mu \mathrm{m}}$ with $R^{2}$ values of 0.99 and 0.78 , respectively. These strong correlations with $N_{>1 \mu \mathrm{m}}$ are again consistent with the notion that the Saharan dust size distribution was reasonably constant, at least within the NAMMA sampling region. This supports the earlier hypothesis by Maring et al. (2003b) and is consistent with the observations by Liu et al. (2008).

Also shown in Table 5 are scattering and absorption Ångström exponents, $\stackrel{\circ}{s p}_{\text {p }}$ and $\stackrel{\circ}{a p}_{\text {p }}$, respectively. The $\stackrel{\circ}{s p}_{\text {is }}$ calculated over the wavelength range of 450 to $700 \mathrm{~nm}$ and $\AA_{\text {ap }}$ is derived between 470 and $660 \mathrm{~nm}$. The background aerosol exhibits larger $\stackrel{\circ}{s p}_{\text {p }}$ and smaller $\stackrel{\circ}{a p}_{\text {palues than the }}$ dust. The $\mathrm{a}_{\mathrm{sp}}$ difference is consistent with earlier discussions on comparison of VMD, indicating background particles are much smaller than dust particles. The background extinction Ångström exponent is averaged at 0.87 with a median value of 0.51 . Previous studies suggest that in cloud free region values $<1$ are indicative of either dust or sea-salt particles or a mix of the two (e.g., Schuster et al., 2006). Available NAMMA data will not be able to resolve detailed aerosol type for background conditions. For the dust layers, the estimated NAMMA $\AA_{\text {sp }}$ and $\AA_{\text {ap }}$ values are generally consistent with those discussed in earlier reports (e.g., Maring et al., 2000; McConnell et al., 2008; Petzold et al., 2009; Schladitz et al., 2009).

An examination of $\omega$ (single scattering albedo) values shows that the dust particles are only weakly absorbing in the visible wavelength range. The SAL average single scattering albedo at $532 \mathrm{~nm}\left(\omega_{532 \mathrm{~nm}}\right)$ is $0.97 \pm 0.01$, compared to $0.91 \pm 0.12$ for the background conditions. The much larger variability for the background estimate is likely due to the larger measurement uncertainty associated with $\sigma_{\text {ap }}(532 \mathrm{~nm})$ values close to the detection limit. The background $\omega_{532 \mathrm{~nm}}$ value itself should be treated with caution. The actual uncertainty associated with $\omega$ assessment should include both atmospheric variability and error propagated from scattering and absorption measurements. This is achieved by combining the standard deviation from Table 5 and error propagation 

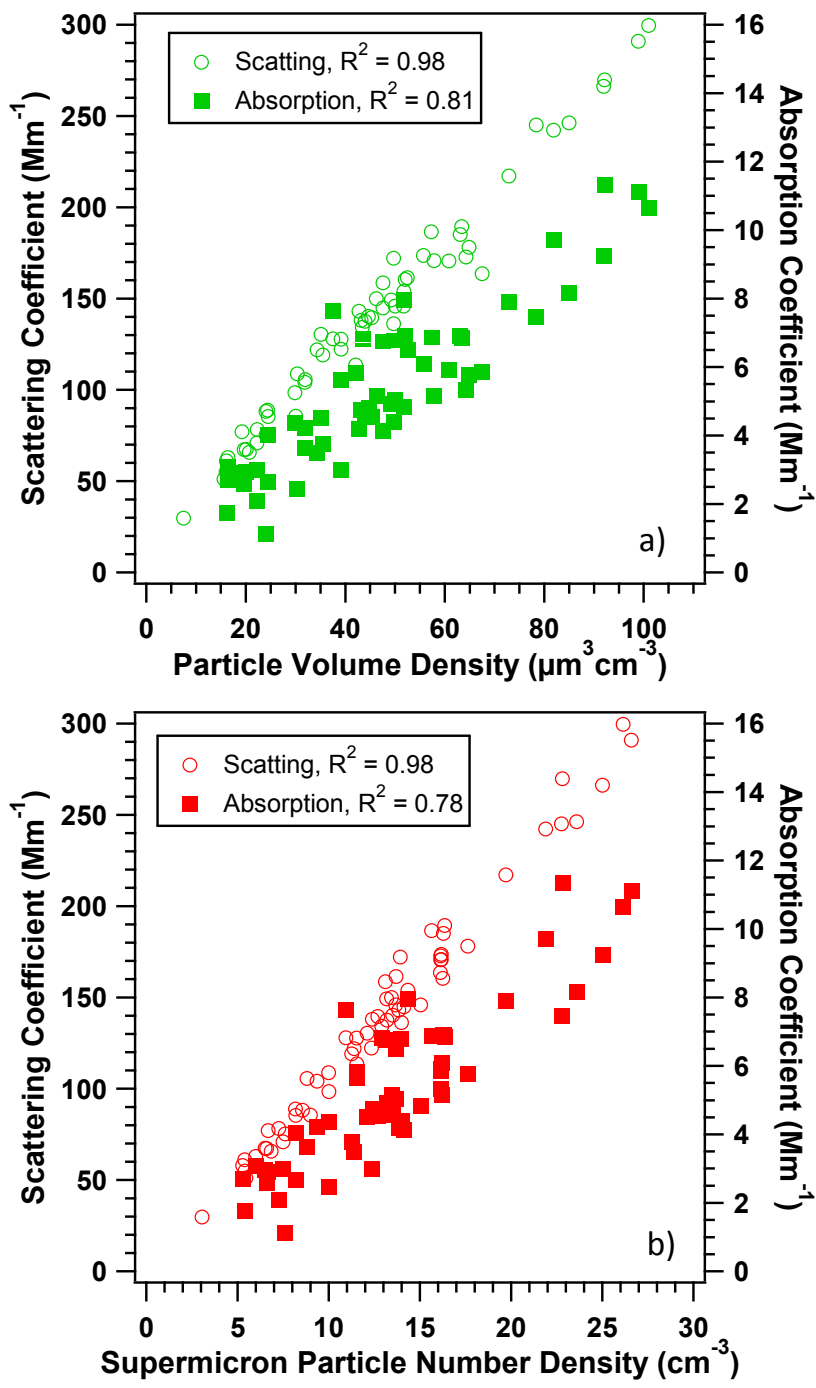

Fig. 7. Scatter plot of the $\sigma_{\mathrm{sp}}(550 \mathrm{~nm})$ and $\sigma_{\mathrm{ap}}(532 \mathrm{~nm})$ coefficients as a function of (a) particle volume density and (b) supermicron particle number density (b).

estimate, which result in a large uncertainty of 0.02 . Thus, we believe the best estimated $\omega_{532} \mathrm{~nm}$ is $0.97 \pm 0.02$. This value agrees well with recently reported in-situ observations of Saharan dust, which ranges from 0.95 to 0.99 (Haywood et al., 2003; McConnell et al., 2008; Osborne et al., 2008; and Schladitz et al., 2009). A value of 0.95 for green wavelengths was estimated from ground-based sunphotometer measurements (e.g., AERONET), which is at the lower end of the range derived from in-situ measurements (Dubovik et al., 2006). It is noted here that our $\omega_{532 \mathrm{~nm}}$ value has a dependence on particle size distribution. If only supermicron dust particles were considered, the Mie-Theory calculation suggests that the $\omega_{532 \mathrm{~nm}}$ value would be 0.94 . This suggests that the NAMMA assessment is likely to represent an upper limit value for SSA due to the inefficient sampling of dust particles larger than $\sim 4 \mu \mathrm{m}$. At the same time, some ground based studies reported similar SSA values derived from observations with much higher efficiency sampling larger particles (e.g., Jeong et al., 2008; Schladitz et al., 2008), which is likely to driven by the chemical composition of dust. It is advised here for modeling studies to use $\omega$ values derived from both in-situ and remote sensing observations. This will be an effective way to address the measurement uncertainties associated with $\omega$ measurement.

\section{Assessment of Saharan dust vertical distributions}

The vertical structure of the SAL was probed during 33 DC8 , near-surface to mid-troposphere soundings. Among those, 3 vertical profiles were performed over the North African continent, just downwind or over a dust source region. The remaining profiles were recorded at various distances offshore, over the east side of MDR. The dust layer centers are between 1.5 and $3.7 \mathrm{~km}$, with a median height of $2.3 \mathrm{~km}$ and their thicknesses, as defined by the half-peak values $\sigma_{\mathrm{sp}}(550 \mathrm{~nm})$, varied from 0.5 to $3 \mathrm{~km}$, with a median value of $1.2 \mathrm{~km}$. By integrating in-situ measurements of scattering and absorption coefficients from the profiles, we were able to assess the impact of the dust on the regional radiation budget. This AOT assessment yielded (dry) values at $532 \mathrm{~nm}$ for the continental-based dust layers that ranged from 0.3 to 0.7 . AOT values for the 30 vertical profiles over the MDR ranged from 0.1 to 0.7 , with a median of 0.4. These estimates are highly consistent with DC-8-based LASE observations (at ambient RH) reported by Ismail et al. (2010) which provided observations with a much more extensive geographical coverage. The in-situ based AOT estimates also fall within the range of monthly averaged AERONET observations on the Sal Island for the period of 1994-1999 (Tanré et al., 2003) and agree well with the average AOT values of 0.3-0.4 derived from MODIS Terra and Aqua data for the NAMMA time period and study area (i.e., $15-30^{\circ} \mathrm{N}$ and $15-30^{\circ} \mathrm{W}$ ), encompassing the NAMMA sampling region.

Figure 8 shows vertical profiles of temperature, $\mathrm{RH}$, and aerosol optical parameters that contrast the vertical distribution of dust over land (dashed line) and ocean (solid line). The data shown on the plots were from two individual DC-8 vertical profiling measurements. The OL (over land) scattering curve in Fig. $8 \mathrm{~b}$ shows that the value of $\sigma_{\mathrm{sp}}(550 \mathrm{~nm})$ is elevated and relatively constant from near surface to approximately $2.5 \mathrm{~km}$, then decreases with altitude. The $\sigma_{\mathrm{sp}}(550 \mathrm{~nm})$

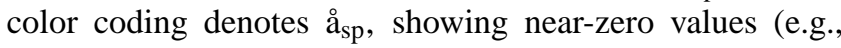
approximately -0.1 and 0.2 ) under approximately $2.5 \mathrm{~km}$. Higher $\AA_{\text {sp }}$ values are seen above $2.5 \mathrm{~km}$ associated with the rapidly decreasing $\sigma_{\mathrm{sp}}(550 \mathrm{~nm})$. The OL potential temperature profile (in Figure 8a) shows that the planetary boundary layer is capped by an inversion at approximately $2.5 \mathrm{~km}$. Thus, NAMMA observations suggest that bulk of the dust layer over land should be confined within the boundary layer. 


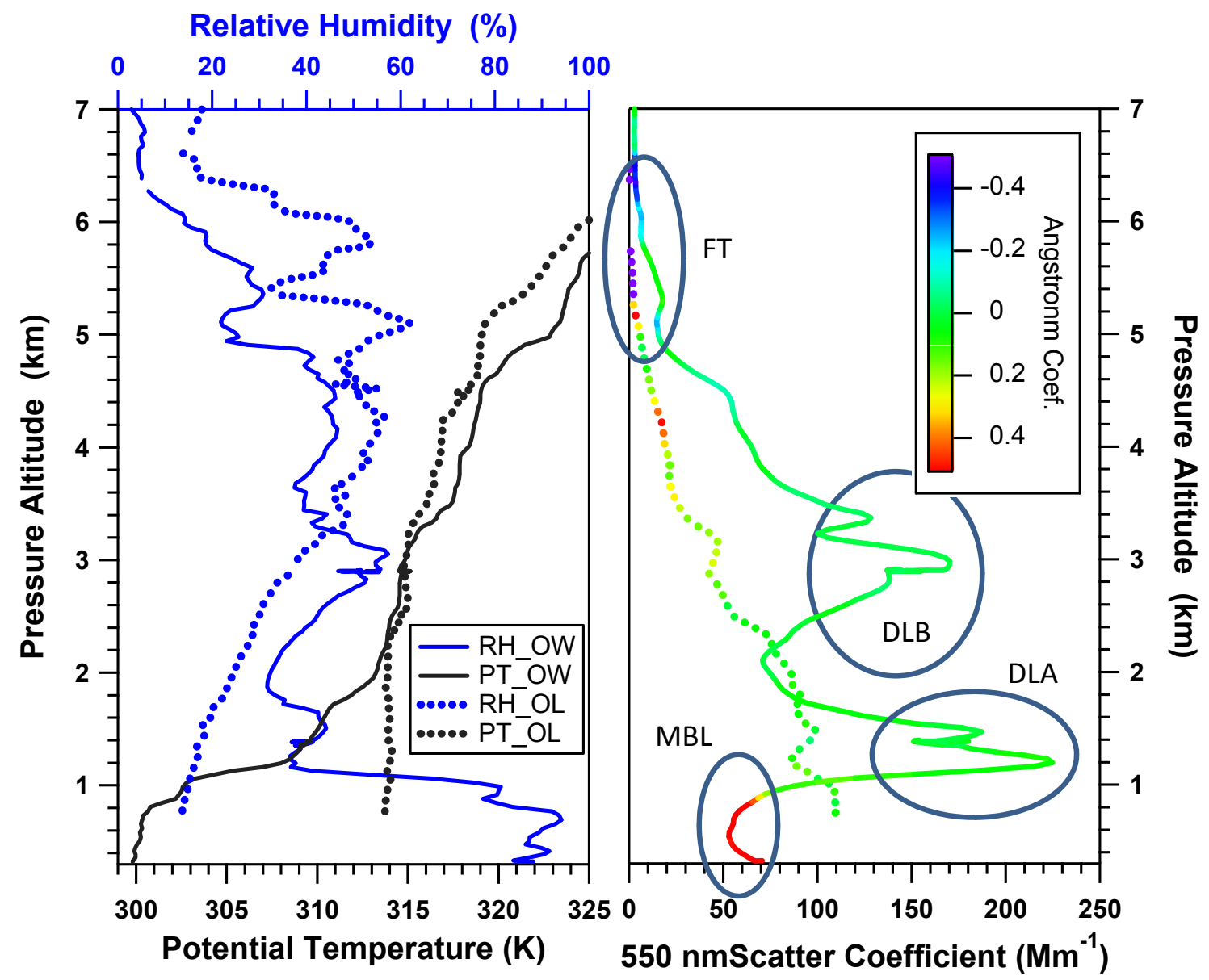

Fig. 8. Vertical profiles of (a) RH and potential temperature and (b) $550 \mathrm{~nm}$ scattering coefficient color coded by Angstrom exponent. The dashed lines (OL) denote measurements over the African continent made on 5 September 2006 during a descent leg from 4 to $0.3 \mathrm{~km}$ and solid lines (OW) indicate the observations over the tropical eastern North Atlantic, taken on 19 August 2006 during an ascent leg from 0.3 to $8 \mathrm{~km}$. Pressure altitude is given in $\mathrm{km}$ above mean sea level.

The RH measurement suggests that the dust layer was very dry, i.e., RH less than $40 \%$. Twohy et al. (2009) reported particles collected at $2.1 \mathrm{~km}$ during this flight were predominately unreacted Saharan dust or dust mixed with soluble material. The OL $\sigma_{\mathrm{sp}}(550 \mathrm{~nm})$ curve shows significantly lower but still elevated values above the main dust layers and the color coding also indicates presence of large particles at certain altitudes. Thus, some dust particles apparently mix up into the free troposphere. These vertical profiles are representative of the NAMMA continental observations and consistent with results from previous land-based studies e.g., McConnell et al., 2008; Heese et al., 2009).

In contrast to the OL observations, the vertical distribution of dust in the offshore regime is much more complex and variable. For example, the over-water $(\mathrm{OW}) \sigma_{\mathrm{sp}}(550 \mathrm{~nm})$ curve (solid line) in Fig. 8b shows two highly-scattering dust layers, DLA and DLB, above a clearly defined marine boundary layer (MBL) inversion at $0.8 \mathrm{~km}$ (see OW potential temperature curve). This type of strongly-capped MBL was often observed in profiles recorded over the MDR during NAMMA. The label "FT" refers to the background free tropospheric altitude regime well above the dust layers which has the lowest $\sigma_{\mathrm{sp}}(550 \mathrm{~nm})$ values and $\mathrm{a}_{\mathrm{sp}}$ values similar to that of dust. The MBL has higher $\sigma_{\mathrm{sp}}(550 \mathrm{~nm})$ values (approximately $60 \mathrm{Mm}^{-1}$ ) and $\AA_{\text {sp }}$ values (approximately 0.5 ) than the FT. Both MBL and FT $\sigma_{\mathrm{sp}}(550 \mathrm{~nm})$ values are significantly lower than those of DLA and DLB. Like the OL case, the dust layer DLA is associated with very dry air layer with RH values often less than $50 \%$. The somewhat higher RH values for DLB (i.e., approaching to $60 \%$ ) may be at least partially attributed the lower temperature (e.g., 4-5K) and mixing with the surrounding airmass.

Particle number and volume size distributions are shown in Fig. 9 to contrast the microphysical properties as a function of altitude for the OW case. The size distributions are displayed as Fig. 9 shows the tri-modal and bimodal (for FT only) lognormal curves. Note that because of instrument problems for the flight, this same type of analysis cannot be 

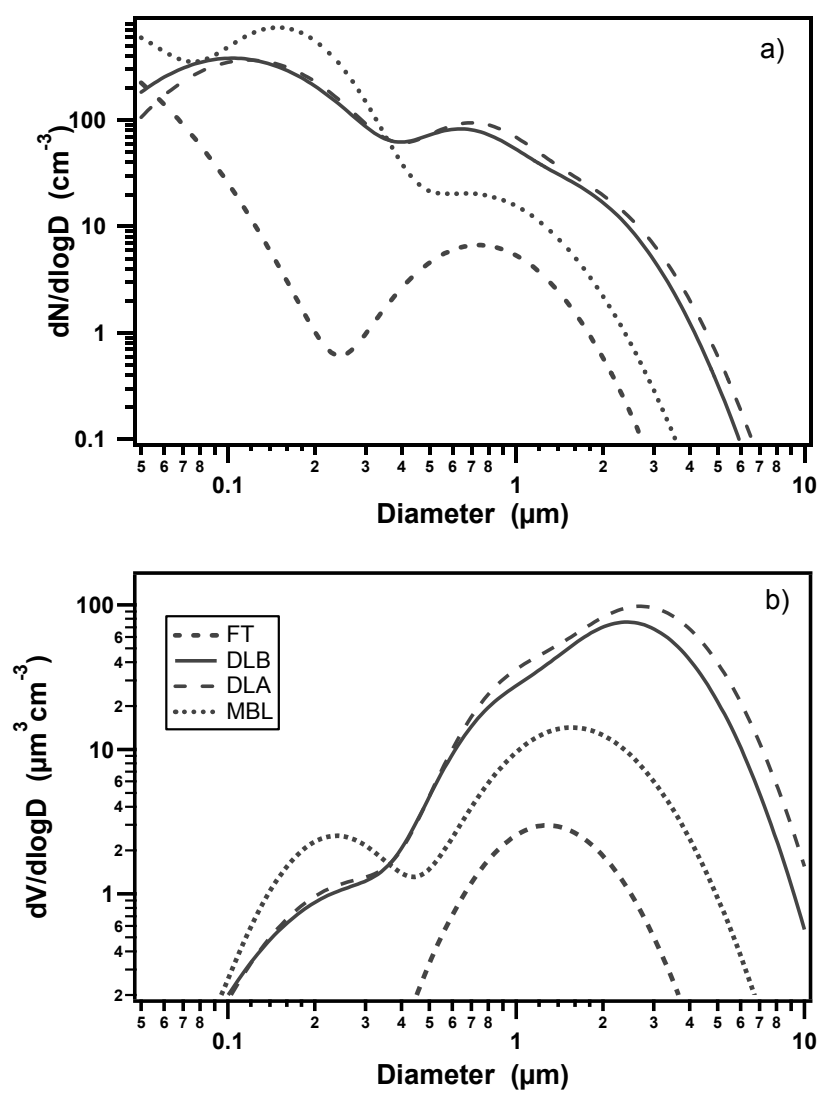

Fig. 9. Comparison of the (a) particle number and (b) volume size distributions as observed for MBL, DLA, DLB, and FT cases label in Fig. 8.

performed for the OL cases. Figure 9a shows that the both MBL and FT may have a nucleation mode, i.e. less than $0.1 \mu \mathrm{m}$; while having significant components in the supermicron mode. The MBL and FT VMD values are estimated at $1.4 \mu \mathrm{m}$ and $1.3 \mu \mathrm{m}$, respectively. The MBL number and volume densities are, however, about 11 and 6 times higher than those of FT, respectively. As displayed in Fig. 9b, the supermicron portion contributes $11 \%$ to the MBL volume density and $26 \%$ to that of FT. Because of high number density in the submicron mode, the MBL submicron surface area density is near $50 \%$ of the total. In contrast, FT submicron contribution is less than $30 \%$. This contrast between MBL and FT may partially account for the difference in $\AA_{\text {sp }}$.

The dust layers DLA and DLB exhibited very similar size distributions, which can be represented by a lognormal fit with three modes at approximately $0.1,0.6$, and $1.4 \mu \mathrm{m}$. For both cases, the submicron mode accounts for over $80 \%$ of the total number density, but less than $10 \%$ of the total volume density. The DLA has about $20 \%$ higher volume density than DLB, but the number densities are nearly identical. The VMD values estimated for the DLA and DLB are 2.2 and $2.0 \mu \mathrm{m}$, respectively. It is interesting to note that the
HYSPLIT trajectory model suggests two distinctly different source regions as well as transport pathways and transport times. DLA originated from the southwestern Sahara near the Atlantic coast and was carried by southeasterly flow to the sampling region in less than $96 \mathrm{~h}$. In contrast, DLB was transported from the southern end of the Sahara desert by the easterly flow within the previous $36 \mathrm{~h}$. These two cases provide more evidence of the size distribution uniformity of the Saharan dust particles, at least in the size range of NAMMA observations.

The MBL $\sigma_{\mathrm{sp}}(550 \mathrm{~nm})$ value shown in Fig. $8 \mathrm{~b}$ represents the median level of all 33 vertical profiles. The overall NAMMA cloud-free (i.e., condensed water content less than $\left.0.01 \mathrm{~g} \mathrm{~m}^{-3}\right)$ median $\sigma_{\mathrm{sp}}(550 \mathrm{~nm})$ derived from all data recorded in the MBL is somewhat higher at $63 \mathrm{Mm}^{-1}$ with a range from 14 to $119 \mathrm{Mm}^{-1}$ (10th and 90th percentiles). The corresponding median extinction value is estimated at $65 \mathrm{Mm}^{-1}$ and the 10th and 90th percentiles are 15 and $121 \mathrm{Mm}^{-1}$. A strong correlation is found between $\sigma_{\mathrm{sp}}(550 \mathrm{~nm})$ and the coarse particle (i.e., $\left.1-5 \mu \mathrm{m}\right)$ volume density, with a $R^{2}$ value of 0.85 . This suggests that the $\sigma_{\mathrm{sp}}(550 \mathrm{~nm})$ variability is predominantly driven by the particle loading, i.e., volume or mass density. Anthropogenic emission influences on NAMMA MBL observations are likely to be quite limited. As evidence, we note that the NAMMA airborne CO measurement showed fairly low and constant values in the MBL (median value at $87 \mathrm{ppbv}$ and 10th and 90th percentiles at 79 and 89 ppbv, respectively) that are characteristic of relatively clean air. Furthermore, the total particle concentrations, ranging from 200 to $1200 \mathrm{~cm}^{-3}$, are also consistent with the typical remote MBL conditions. As discussed earlier, the major $>0.1 \mu \mathrm{m}$ particle types observed during NAMMA were Saharan dust and sea-salt or its derivatives. It is well known that both surface emission and loss of the sea-salt particles are strong functions of wind speed. Mulcahy et al. (2008) showed strong correlation between AOT and "steady-state" wind. In contrast, the analysis by Witek et al. (2007) revealed a more complicated relationship between in-situ wind and the sea-salt mass loading. In the case of NAMMA DC- 8 observations, the overall correlation between $\sigma_{\mathrm{sp}}(550 \mathrm{~nm})$ and wind speed is extremely weak (i.e., $R^{2}$ of approximately 0.02 ). The DC-8 wind measurement is an instantaneous reading, which may not accurately represent the large scale wind field if it is temporally and/or spatially inhomogeneous. In this context, the interpretation of this weak correlation may result from wind-field inhomogeneity or alternatively, significant presence of the dust particles, which may be either from downward mixing from the overriding SAL or MBL advective transports from the source regions. It is noted that downward transport of SAL dust particles was sampled from time to time in MBL by Jeong et al. (2008) at a surface station on the Sal Island, Cape Verde during the NAMMA sampling period. 


\section{Summary and conclusions}

Multiple free tropospheric Saharan dust layers were sampled during the 62 encounters in the eastern North Atlantic during the NAMMA airborne campaign, which took place in August and September, 2006. The layers were identified, under cloud free conditions, by having elevated aerosol scattering coefficients, enhanced coarse mode particle concentrations and near-zero values of scattering Ångström exponent. The NAMMA study area extended over the region between 10 $25^{\circ} \mathrm{N}$ and $10-35^{\circ} \mathrm{W}$, which overlaps the eastern part of the Hurricane Main Development Region. The particle vertical profiles recorded downwind of African dust source regions showed complicated structures, with multiple dust layers, at times, in the altitude regimes above the strongly-capped MBL inversion. The centers of these layers were mostly located between 1.5 and $3.3 \mathrm{~km}$ and layer thicknesses ranged from 0.5 to $3 \mathrm{~km}$, with a median value of $1.2 \mathrm{~km}$. In contrast, profiles recorded over the continent near dust source regions exhibited a much simpler vertical structure, with dust loadings that were relatively constant throughout the boundary layer, but dropped sharply at altitudes above approximately $2.5 \mathrm{~km}$. These findings are generally in agreement with previous studies.

It is acknowledged here that the NAMMA dust particle microphysical and optical observations were carried out using the sampling inlet with a size cut of $5 \mu \mathrm{m}$ in aerodynamic diameter, which is equivalent to approximately $4 \mu \mathrm{m}$ for dust particles. The observed dust layers exhibited relatively low particle number densities (268 to $461 \mathrm{~cm}^{-3}$ ) but rather enhanced volume densities (20 to $79 \mu \mathrm{m}^{3} \mathrm{~cm}^{-3}$ ). Volatility measurements show that $\geq \sim 70 \%$ (on average) of the particle population was non-volatile. Combined UHSAS and APS measurements of dust particle size distributions can be represented by tri-modal lognormal distributions, peaking at diameters of $0.1,0.6$ and $1.1 \mu \mathrm{m}$. Case studies showed very similar size distributions for two dust layers that had undergone different transport processes and originated from difference source regions. This finding is consistent with the small variability in the NAMMA observed VMD (volume median diameter) values. Both these NAMMA observations suggest that the Saharan dust particle size distribution have weak dependence on transport distance (both vertical and horizontal) and/or time as well as source regions. Similar findings have been reported in previous studies.

The NAMMA aerosol optical property measurements show that Sahara dust particles are strong-scattering and weak-absorbing in nature. The weak dust absorbance, however, has strong wavelength dependence, with an average Ångström exponent at 4.1. The average green single scattering albedo was $0.97 \pm 0.02$ and the mass extinction efficiency was $1.09 \mathrm{~m}^{2} \mathrm{~g}^{-1}$. The vertical integrated AOT value ranged from 0.3 to 0.7 which is consistent with the NAMMA LASE measurement and with values reported from other studies.
It is shown in the scattering closure test and absorption comparison that the size distribution measurements were highly correlated with independent measurements of absorption and scattering coefficients. An $R^{2}$ value of 0.99 was estimated for the nephelometer observed scattering coefficient and the values obtained from the spherical Mie-Theory calculation based on the observed dust particle size distributions. The corresponding slope of 0.76 , indicating $24 \%$ underestimate from the calculated, is consistent with the similar previous studies. The closure results provide a quantitative basis for a comprehensive model assessment of both Sahara dust microphysical and optical properties. At the same time, this study again demonstrates the need for future laboratory and field studies to identify the factors that limits our ability to achieve a full closure in scattering coefficient.

The NAMMA estimated VMD value is a factor of 2 smaller than observed in a number of previous Saharan dust studies. Similarly, the NAMMA effective radius is about $15 \%$ smaller than the MODIS retrieved value. Both these findings are at least qualitatively consistent with the fact the NAMMA in-situ sampling inlet has a 50\% size-cut for approximately $4 \mu \mathrm{m}$-diameter particles, which limits the ability to sample particles with larger diameters. This size cut may have significant impact on NAMMA dust volume and mass loading assessments. Future studies should examine this potential flaw in NAMMA observations. Furthermore, additional measurements investigating the relationship between the dust particle optical properties and chemical composition as well as to the extent of the MBL dust particle presence would be useful.

Acknowledgements. This work was supported by the NASA Radiation Science Program, Atmospheric Chemistry Modeling and Analysis Program, and Tropospheric Chemistry Program. Dr. Reid's participation was funded by NASA Radiation Sciences and ONR 32. The authors would like to thank the DC-8 crew and the NAMMA science team for making this work possible.

Edited by: T. J. Dunkerton

\section{References}

Anderson, T. L. and Ogren, J. A.: Determining aerosol radiative properties using the tsi 3563 integrating nephelometer, Aerosol Sci. Technology, 29, 57-69, 1998.

Anderson, T. L., Covert, D. S., Marshall, S. F., Laucks, M. L., Charlson, R. J., Waggoner, A. P., Ogren, J. A., Caldow, R., Holm, R. L., Quant, F. R., Sem, G. J., Wiedensohler, A., Ahlquist, N. A., and Bates, T. S.: Performance characteristics of a high-sensitivity, three-wavelength, total scatter/backscatter nephelometer, J. Atmos. Ocean. Tech., 13, 967-986, 1996.

Bohren, C. F. and Huffman, D. R.: Absorption and Scattering of Light by Small Particles, Wiley, New York, 1983.

Cai, Y., Montague, D. C., Mooiweer-Bryan, W., and Deshler, T.: Performance characteristics of the ultra high sensitivity aerosol spectrometer for particles between 55 and $800 \mathrm{~nm}$ : Laboratory and field studies, J. Aerosol Sci., 39, 759-769, doi:10.1016/j.jaerosci.2008.04.007, 2008. 
Clarke, A., McNaughton, C., Kapustin, V., Shinozuka, Y., Howell, S., Dibb, J., Zhou, J., Anderson, B., Brekhovskikh, V., Turner, H., and Pinkerton, M.: Biomass burning and pollution aerosol over north america: Organic components and their influence on spectral optical properties and humidification response, J. Geophys. Res.-Atmos., 112, D12s18, doi:10.1029/2006jd007777, 2007.

DeMott, P. J., Sassen, K., Poellot, M. R., Baumgardner, D., Rogers, D. C., Brooks, S. D., Prenni, A. J., and Kreidenweis, S. M.: African dust aerosols as atmospheric ice nuclei, Geophys. Res. Lett., 30, 1732, doi:10.1029/2003g1017410, 2003.

Draxler, R. R. and Rolph, G. D.: HYSPLIT (HYbrid SingleParticle Lagrangian Integrated Trajectory) Model access via NOAA ARL READY Website, available at: http://ready.arl. noaa.gov/HYSPLIT.php,NOAAAirResourcesLaboratory, Silver Spring, MD, 2010.

Dubovik, O., Sinyuk, A., Lapyonok, T., Holben, B. N., Mishchenko, M., Yang, P., Eck, T. F., Volten, H., Munoz, O., Veihelmann, B., van der Zande, W. J., Leon, J. F., Sorokin, M., and Slutsker, I.: Application of spheroid models to account for aerosol particle nonsphericity in remote sensing of desert dust, J. Geophys. Res.-Atmos., 111, D11208, doi:10.1029/2005jd006619, 2006.

Dunion, J. P. and Velden, C. S.: The impact of the saharan air layer on atlantic tropical cyclone activity, B. Am. Meteorol. Soc., 85, 353-365, doi:10.1175/bams-85-3-353, 2004.

Eck, T. F., Holben, B. N., Reid, J. S., Dubovik, O., Smirnov, A., O'Neill, N. T., Slutsker, I., and Kinne, S.: Wavelength dependence of the optical depth of biomass burning, urban, and desert dust aerosols, J. Geophys. Res.-Atmos., 104, $31333-$ 31349, 1999.

Haywood, J., Francis, P., Dubovik, O., Glew, M., and Holben, B.: Comparison of aerosol size distributions, radiative properties, and optical depths determined by aircraft observations and sun photometers during safari 2000, J. Geophys. Res.-Atmos., 108, 8471, doi:10.1029/2002jd002250, 2003.

Heese, B., Althausen, D., Dinter, T., Esselborn, M., Muller, E. T., Tesche, M., and Wiegner, M.: Vertically resolved dust optical properties during samum: Tinfou compared to ouarzazate, Tellus B, 61, 195-205, doi:10.1111/j.1600-0889.2008.00404.x, 2009.

Heintzenberg, J.: The samum-1 experiment over southern morocco: Overview and introduction, Tellus B, 61, 2-11, doi:10.1111/j.1600-0889.2008.00403.x, 2009.

Heintzenberg, J., Wiedensohler, A., Tuch, T. M., Covert, D. S., Sheridan, P., Ogren, J. A., Gras, J., Nessler, R., Kleefeld, C., Kalivitis, N., Aaltonen, V., Wilhelm, R. T., and Havlicek, M.: Intercomparisons and aerosol calibrations of 12 commercial integrating nephelometers of three manufacturers, J. Atmos. Ocean. Tech., 23, 902-914, 2006.

Holben, B. N., Eck, T. F., and Fraser, R. S.: Temporal and spatial variability of aerosol optical depth in the sahel region in relation to vegetation remote-sensing, Int. J. Remote Sens., 12, 1147$1163,1991$.

Ismail, S., Ferrare, R. A., Browell, E. V., Kooi, S. A., Dunion, J. P., Heymsfield, G., Notari, A., Butler, C. F., Burton, S., Fenn, M., Krishnamurti, T. N., Biswas, M. K., Chen, G., and Anderson, B.: Lase measurements of water vapor, aerosol, and cloud distributions in Saharan air layers and tropical disturbances, J. Atmos. Sci., 67, 1026-1047, doi:10.1175/2009jas3136.1, 2010.
Jeong, M. J., Tsay, S. C., Ji, Q., Hsu, N. C., Hansell, R. A., and Lee, J.: Ground-based measurements of airborne saharan dust in marine environment during the NAMMA field experiment, Geophys. Res. Lett., 35, L20805, doi:10.1029/2008g1035587, 2008.

Kaufman, Y. J., Koren, I., Remer, L. A., Tanre, D., Ginoux, P., and Fan, S.: Dust transport and deposition observed from the terramoderate resolution imaging spectroradiometer (modis) spacecraft over the atlantic ocean, J. Geophys. Res.-Atmos., 110, D10s12, doi:10.1029/2003jd004436, 2005.

Kalashnikova, O. V. and Sokolik, I. N.: Importance of shapes and compositions of wind-blown dust particles for remote sensing at solar wavelengths, Geophys. Res. Lett., 29, 1398, doi:139810.1029/2002g1014947, 2002.

Lack, D. A., Cappa, C. D., Covert, D. S., Baynard, T., Massoli, P., Sierau, B., Bates, T. S., Quinn, P. K., Lovejoy, E. R., and Ravishankara, A. R.: Bias in filter-based aerosol light absorption measurements due to organic aerosol loading: Evidence from ambient measurements, Aerosol Sci. Technol., 42, 1033-1041, doi:10.1080/02786820802389277, 2008.

Lau, K. M. and Kim, K. M.: Cooling of the atlantic by saharan dust, Geophys. Res. Lett., 34, L23811, doi:10.1029/2007g1031538, 2007.

Liu, Z. Y., Sugimoto, N., and Murayama, T.: Extinction-tobackscatter ratio of asian dust observed with high-spectralresolution lidar and raman lidar, Appl. Optics, 41, 2760-2767, 2002.

Liu, Z. Y., Omar, A., Vaughan, M., Hair, J., Kittaka, C., Hu, Y. X., Powell, K., Trepte, C., Winker, D., Hostetler, C., Ferrare, R., and Pierce, R.: Calipso lidar observations of the optical properties of saharan dust: A case study of long-range transport, J. Geophys. Res.-Atmos., 113, D07207, doi:10.1029/2007jd008878, 2008.

Maring, H., Savoie, D. L., Izaguirre, M. A., McCormick, C., Arimoto, R., Prospero, J. M., and Pilinis, C.: Aerosol physical and optical properties and their relationship to aerosol composition in the free troposphere at izana, tenerife, canary islands, during July 1995, J. Geophys. Res.-Atmos., 105, 14677-14700, 2000.

Maring, H., Savioe, D. L., Izaguirre, M. A., Custals, L., and Reid, J. S.: Vertical distributions of dust and sea-salt aerosols over Puerto Rico during pride measured from a light aircraft, J. Geophys. Res.-Atmos., 108, 8587, doi:10.1029/2002jd002544, $2003 \mathrm{a}$.

Maring, H., Savoie, D. L., Izaguirre, M. A., Custals, L., and Reid, J. S.: Mineral dust aerosol size distribution change during atmospheric transport, J. Geophys. Res.-Atmos., 108, 8592, doi:10.1029/2002jd002536, 2003b.

McConnell, C. L., Highwood, E. J., Coe, H., Formenti, P., Anderson, B., Osborne, S., Nava, S., Desboeufs, K., Chen, G., and Harrison, M. A. J.: Seasonal variations of the physical and optical characteristics of saharan dust: Results from the dust outflow and deposition to the ocean (dodo) experiment, J. Geophys. Res.Atmos., 113, D14s05, doi:10.1029/2007jd009606, 2008.

McNaughton, C. S., Clarke, A. D., Howell, S. G., Pinkerton, M., Anderson, B., Thornhill, L., Hudgins, C., Winstead, E., Dibb, J. E., Scheuer, E., and Maring, H.: Results from the dc-8 inlet characterization experiment (dice): Airborne versus surface sampling of mineral dust and sea salt aerosols, Aerosol Sci. Technol., 41, 136-159, doi:10.1080/02786820601118406, 2007.

Mulcahy, J. P., O’Dowd, C. D., Jennings, S. G., and Ceburnis, D.: Significant enhancement of aerosol optical depth in marine air under high wind conditions, Geophys. Res. Lett., 35, L16810, 
doi:10.1029/2008g1034303, 2008.

Omar, A. Z. Liu, M., Vaughan, K. L., Thornhill, C., Kittaka, S., Ismail, Y., Hu, G., Chen, D., Winker, C., Trepte, E. L., Winstead, and Anderson, B. E: Extinction- to -backscatter ratios of Saharan dust layers derived from in situ measurements and CALIPSO overflights during NAMMA, J. Geophys. Res., 115, D24217, doi:10.1029/2010JD014223, 2010.

Osborne, S. R., Johnson, B. T., Haywood, J. M., Baran, A. J., Harrison, M. A. J., and McConnell, C. L.: Physical and optical properties of mineral dust aerosol during the dust and biomassburning experiment, J. Geophys. Res.-Atmos., 113, D00c03, doi:10.1029/2007jd009551, 2008.

Petzold, A., Rasp, K., Weinzierl, B., Esselborn, M., Hamburger, T., Dornbrack, A., Kandler, K., Schutz, L., Knippertz, P., Fiebig, M., and Virkkula, A.: Saharan dust absorption and refractive index from aircraft-based observations during samum 2006, Tellus B, 61, 118-130, doi:10.1111/j.1600-0889.2008.00383.x, 2009.

Quirantes, A., Olmo, F. J., Lyamani, H., and Alados-Arboledas, L.: Correction factors for a total scatter/backscatter nephelometer, J. Quant. Spectrosc. Ra. , 109, 1496-1503, doi:10.1016/j.jqsrt.2007.12.014, 2008.

Reid, J. S., Jonsson, H. H., Maring, H. B., Smirnov, A., Savoie, D. L., Cliff, S. S., Reid, E. A., Livingston, J. M., Meier, M. M., Dubovik, O., and Tsay, S. C.: Comparison of size and morphological measurements of coarse mode dust particles from africa, J. Geophys. Res.-Atmos., 108, 8593, doi:10.1029/2002jd002485, 2003.

Reid, J. S., Brooks, B., Crahan, K. K., Hegg, D. A., Eck, T. F., O'Neill, N., de Leeuw, G., Reid, E. A., and Anderson, K. D.: Reconciliation of coarse mode sea-salt aerosol particle size measurements and parameterizations at a subtropical ocean receptor site, J. Geophys. Res.-Atmos., 111, D02202, doi:10.1029/2005jd006200, 2006.

Reid, J. S., Reid, E. A., Walker, A., Piketh, S., Cliff, S., Al Mandoos, A., Tsay, S. C., and Eck, T. F.: Dynamics of southwest asian dust particle size characteristics with implications for global dust research, J. Geophys. Res.-Atmos., 113, D14212, doi:10.1029/2007jd009752, 2008.

Remer, L. A., Tanre, D., Kaufman, Y. J., Ichoku, C., Mattoo, S., Levy, R., Chu, D. A., Holben, B., Dubovik, O., Smirnov, A., Martins, J. V., Li, R. R., and Ahmad, Z.: Validation of modis aerosol retrieval over ocean, Geophys. Res. Lett., 29, 1618, doi:161810.1029/2001g1013204, 2002.

Rosenfeld, D., Rudich, Y., and Lahav, R.: Desert dust suppressing precipitation: A possible desertification feedback loop, P. Natl. Acad. Sci. USA, 98, 5975-5980, 2001.

Sassen, K., DeMott, P. J., Prospero, J. M., and Poellot, M. R.: Saharan dust storms and indirect aerosol effects on clouds: Crystal-face results, Geophys. Res. Lett., 30, 1633, doi:10.1029/2003g1017371, 2003.

Schladitz, A., Muller, T., Kaaden, N., Massling, A., Kandler, K., Ebert, M., Weinbruch, S., Deutscher, C., and Wiedensohler, A.: In-situ measurements of optical properties at tinfou (morocco) during the saharan mineral dust experiment samum 2006, Tellus B, 61, 64-78, doi:10.1111/j.1600-0889.2008.00397.x, 2009.

Schuster, G. L., Dubovik, O., and Holben, B. N.: Angstrom exponent and bimodal aerosol size distributions, J. Geophys. Res.Atmos., 111, D07207, doi:10.1029/2005jd006328, 2006.

Sun, D. L., Lau, K. M., and Kafatos, M.: Contrasting the 2007 and
2005 hurricane seasons: Evidence of possible impacts of saharan dry air and dust on tropical cyclone activity in the atlantic basin, Geophys. Res. Lett., 35, L15405, doi:10.1029/2008g1034529, 2008.

Tanre, D., Kaufman, Y. J., Herman, M., and Mattoo, S.: Remote sensing of aerosol properties over oceans using the modis/eos spectral radiances, J. Geophys. Res.-Atmos., 102, 16971-16988, 1997.

Tanre, D., Haywood, J., Pelon, J., Leon, J. F., Chatenet, B., Formenti, P., Francis, P., Goloub, P., Highwood, E. J., and Myhre, G.: Measurement and modeling of the saharan dust radiative impact: Overview of the saharan dust experiment (shade), J. Geophys. Res.-Atmos., 108, 8574, doi:10.1029/2002jd003273, 2003.

Thornhill, K. L., Chen, G., Dibb, J., Jordan, C. E., Omar, A., Winstead, E. L., Schuster, G., Clarke, A., McNaughton, C., Scheuer, E., Blake, D., Sachse, G., Huey, L. G., Singh, H. B., and Anderson, B. E.: The impact of local sources and longrange transport on aerosol properties over the northeast us region during intex-na, J. Geophys. Res.-Atmos., 113, D08201, doi:10.1029/2007jd008666, 2008.

Twohy, C. H., Kreidenweis, S. M., Eidhammer, T., Browell, E. V., Heymsfield, A. J., Bansemer, A. R., Anderson, B. E., Chen, G., Ismail, S., DeMott, P. J., and Van den Heever, S. C.: Saharan dust particles nucleate droplets in eastern atlantic clouds, Geophys. Res. Lett., 36, L01807, doi:10.1029/2008g1035846, 2009.

van den Heever, S. C., Carrio, G. G., Cotton, W. R., DeMott, P. J., and Prenni, A. J.: Impacts of nucleating aerosol on florida storms. Part i: Mesoscale simulations, J. Atmos. Sci., 63, 17521775, 2006.

Velden, C., Daniels, J., Stettner, D., Santek, D., Key, J., Dunion, J., Holmlund, K., Dengel, G., Bresky, W., and Menzel, P.: Recent innovations in deriving tropospheric winds from meteorological satellites, B. Am. Meteorol. Soc., 86, 205-223, doi:10.1175/bams-86-2-205, 2005.

Virkkula, A., Ahlquist, N. C., Covert, D. S., Arnott, W. P., Sheridan, P. J., Quinn, P. K., and Coffman, D. J.: Modification, calibration and a field test of an instrument for measuring light absorption by particles, Aerosol Sci. Technol., 39, 68-83, doi:10.1080/027868290901963, 2005.

Witek, M. L., Flatau, P. J., Quinn, P. K., and Westphal, D. L.: Global sea-salt modeling: Results and validation against multicampaign shipboard measurements, J. Geophys. Res.-Atmos., 112, D08215, doi:10.1029/2006jd007779, 2007.

Zhang, H., McFarquhar, G. M., Saleeby, S. M., and Cotton, W. R.: Impacts of saharan dust as cen on the evolution of an idealized tropical cyclone, Geophys. Res. Lett., 34, L14812, doi:10.1029/2007g1029876, 2007.

Zhang, H. N., McFarquhar, G. M., Cotton, W. R., and Deng, Y.: Direct and indirect impacts of saharan dust acting as cloud condensation nuclei on tropical cyclone eyewall development, Geophys. Res. Lett., 36, L06802, doi:10.1029/2009g1037276, 2009.

Zipser, E. J., Twohy, C. H., Tsay, S. C., Thornhill, K. L., Tanelli, S., Ross, R., Krishnamurti, T. N., Ji, Q., Jenkins, G., Ismail, S., Hsu, N. C., Hood, R., Heymsfield, G. M., Heymsfield, A., Halverson, J., Goodman, H. M., Ferrare, R., Dunion, J. P., Douglas, M., Cifelli, R., Chen, G., Browell, E. V., and Anderson, B.: The saharan air layer and the fate of african easterly waves, B. Am. Meteorol. Soc., 90, 1137-1156, doi:10.1175/2009bams2728.1, 2009. 